\title{
Poly(ADP-ribose) polymerase inhibitors activate the p53 signaling pathway in neural stem/progenitor cells
}

\author{
Akiko Okuda ${ }^{1,4^{\dagger}}$, Suguru Kurokawa ${ }^{1 \dagger}$, Masanori Takehashi ${ }^{1}$, Aika Maeda ${ }^{1}$, Katsuya Fukuda ${ }^{1}$, Yukari Kubo ${ }^{1}$, \\ Hyuma Nogusa ${ }^{1}$, Tomoka Takatani-Nakase ${ }^{1,5}$, Shujiro Okuda² ${ }^{2}$ Kunihiro Ueda ${ }^{3}$ and Seigo Tanaka ${ }^{{ }^{*}}$ (0)
}

\begin{abstract}
Background: Poly(ADP-ribose) polymerase 1 (PARP-1), which catalyzes poly(ADP-ribosyl)ation of proteins by using $\mathrm{NAD}^{+}$as a substrate, plays a key role in several nuclear events, including DNA repair, replication, and transcription. Recently, PARP-1 was reported to participate in the somatic cell reprogramming process. Previously, we revealed a role for PARP-1 in the induction of neural apoptosis in a cellular model of cerebral ischemia and suggested the possible use of PARP inhibitors as a new therapeutic intervention. In the present study, we examined the effects of PARP inhibitors on neural stem/progenitor cells (NSPCS) of the mouse brain.

Results: PARP-1 was more abundant and demonstrated higher activity in NSPCS than in mouse embryonic fibroblasts. Treatment with PARP inhibitors suppressed the formation of neurospheres by NSPCs through the suppression of cell cycle progression and the induction of apoptosis. In order to identify the genes responsible for these effects, we investigated gene expression profiles by microarray analyses and found that several genes in the p53 signaling pathway were upregulated, including Cdkn1a, which is critical for cell cycle control, and Fas, Pidd, Pmaip 1, and Bbc3, which are principal factors in the apoptosis pathway. Inhibition of poly(ADP-ribosyl)ation increased the levels of p53 protein, but not p53 mRNA, and enhanced the phosphorylation of p53 at Ser18. Experiments with specific inhibitors and also shRNA demonstrated that PARP-1, but not PARP-2, has a role in the regulation of $\mathrm{p} 53$. The effects of PARP inhibitors on NSPCs were not observed in Trp53 ${ }^{-1-}$ NSPCs, suggesting a key role for p53 in these events.
\end{abstract}

Conclusions: On the basis of the finding that PARP inhibitors facilitated the p53 signaling pathway, we propose that poly(ADP-ribosyl)ation contributes to the proliferation and self-renewal of NSPCS through the suppression of p53 activation.

Keywords: Poly(ADP-ribosyl)ation, Poly(ADP-ribose) polymerase, Neural stem/progenitor cells, p53, Cell cycle, Apoptosis

\section{Background}

Poly(ADP-ribose) polymerase-1 (PARP-1) and PARP-2 belong to the PARP family, which consists of 17 predicted members that share a catalytic domain homologous to that of PARP-1 $[1,2]$. These enzymes use NAD ${ }^{+}$

\footnotetext{
${ }^{*}$ Correspondence: tanakase@osaka-ohtani.ac.jp

${ }^{\dagger}$ Akiko Okuda and Suguru Kurokawa contributed equally to this work

${ }^{1}$ Laboratory of Pathophysiology and Pharmacotherapeutics,

Faculty of Pharmacy, Osaka Ohtani University, 3-11-1 Nishikiori-kita,

Tondabayashi, Osaka 584-8540, Japan

Full list of author information is available at the end of the article
}

as a substrate, synthesize ADP-ribose molecules, and transfer them onto the glutamate, aspartate, or lysine residues of acceptor proteins. Poly(ADP-ribosyl)ation regulates nuclear functions and responses that include DNA repair, replication, transcription, and chromatin modification. After exposure to genotoxic chemicals, such as DNA alkylating agents, PARP-1 binds to the DNA strand breaks, resulting in a change of conformation and increase of its enzymatic activity by $10-500$ fold [3-5]. The modified acceptor proteins, including histones and PARP-1 itself, greatly change their size by harboring 
up to several hundred ADP-ribose residues $[2,6]$. The polyanionic structure thus formed counteracts the inhibitory effect of histones on DNA ligase. Conversely, excessive activation of PARP-1 and depletion of $\mathrm{NAD}^{+}$after severe DNA damage cause cell death by ATP depletion or an "energy crisis" [7, 8]. Previously, we reported a principal role for PARP-1 in the induction of mitochondrial impairment that ultimately leads to neuronal apoptosis after cerebral ischemia [9], indicating that PARP inhibitors could be a good therapeutic intervention for cerebral infarction.

PARP inhibitors such as 3-aminobenzamide (3AB) interact with the nicotinamide pocket of PARP-1, which is a highly conserved region in the catalytic domain of PARPs, and act as competitors of $\mathrm{NAD}^{+}[10,11]$. Therefore, these inhibitors can suppress the activity of various PARPs with a homogeneous catalytic domain. More recently, however, several PARP inhibitors selective for PARP-1 or PARP-2 have been developed to study their specific function or potential therapeutic application [12]. As little is known about the effects of PARP inhibitors on somatic stem cells, these effects should be taken into consideration, particularly for their clinical use.

In the adult human and rodent brain, neural stem/progenitor cells (NSPCs) exist in the subventricular zone of the lateral ventricles and propagate to the olfactory bulb $[13,14]$. NSPCs are also present in the subgranular zone of the hippocampal dentate gyrus and possibly contribute to spatial memory formation and cognition [15]. In these regions, neurogenesis occurs even in physiological conditions. However, under various types of brain injury, such as stroke, epileptic seizures, and trauma, the generation and proliferation of neural precursor cells are induced both in the subgranular and subventricular zones. The majority of neurons generated in the subventricular zone migrate toward the lesion site to replace damaged neurons and induce neural regeneration [16].

Mutation of the $p 53$ gene is observed frequently in cancer [17]. The function of p53 as a tumor suppressor depends principally on its ability to suppress cellular proliferation that would otherwise form tumor tissue. Activation of p53 induces cell cycle arrest and apoptosis $[18,19]$. These functions of p53 result from its role as a transcription factor [20,21]. Among the identified p53-target genes, p21 plays a critical role in the induction of cell cycle arrest [22, 23]. p21 is a cyclin-dependent kinase inhibitor that induces both the G1 and G2 cell cycle arrest observed after p53 activation [24-26]. Conversely, p53 induces apoptosis by activating some genes that participate in the apoptotic response. Furthermore, p53 plays a critical role in preventing the reprogramming of cells carrying various types of DNA damage [27].
Silencing of p53 significantly enhances the efficiency of the reprogramming of human somatic cells [28].

In the present study, we investigated the effects of PARP inhibitors on NSPCs in the adult brain and found two different effects, i.e., suppression of cell cycle progression and induction of apoptosis. Interestingly, both effects are mediated by the activation of p53. It is worthy of special mention that more poly(ADP-ribosyl)ated proteins existed in NSPCs than in mouse embryonic fibroblasts (MEFs). On the basis of these results, PARP, or poly(ADP-ribosyl)ation, could play a principal role in the maintenance of NSPC multipotency through the suppression of p53 function.

\section{Methods}

\section{Separation and passage of NSPCs}

All experimental protocols conformed to the Fundamental Guidelines for Proper Conduct of Animal Experiment and Related Activities in Academic Research Institutions under the jurisdiction of the Ministry of Education, Culture, Sports, Science, and Technology, Japan, and all experiments were approved by the Animal Experiment Committee of Osaka Ohtani University (No. 1012). NSPCs were obtained from Slc:ICR mouse embryos (embryonic day 13.5) as described previously [29-31]. The cells were dissociated and suspended at a density of $2.0 \times 10^{6}$ cells in 100 -mm dishes in $1 \times$ Dulbecco's modified Eagle's medium (DMEM)/F-12 neurosphere medium supplemented with B-27 (Gibco), $20 \mathrm{ng} / \mathrm{mL}$ human recombinant epidermal growth factor (EGF) (PeproTech), and $20 \mathrm{ng} / \mathrm{mL}$ human recombinant fibroblast growth factor (FGF)-basic (PeproTech). The culture medium was changed every other day and the cells were dissociated by using StemPro Accutase (Life Technologies) every 4 days. The cells were passaged 3-5 times. Untreated bacterial-grade culture dishes were used for suspension cultures, whereas dishes coated with poly-L-ornithine and fibronectin were used for monolayer cultures.

\section{Trp53 deficient mice}

Trp53-heterozygous mice (accession no. CDB0001K) [32] were obtained from the RIKEN BioResource Center. Genotyping for the $\operatorname{Tr} p 53$ allele was performed by polymerase chain reaction (PCR) with primer 1 ( $5^{\prime}$-gttatgcatccatacag taca- $\left.3^{\prime}\right)$ and primer $2\left(5^{\prime}\right.$-caggatatcttctggaggaag- $\left.3^{\prime}\right)$.

\section{PARP inhibitors}

$N$-(6-oxo-5,6-dihydro-phenanthridin-2-yl)- $N, N$-dimethylacetamide (PJ34; Calbiochem), 1,5-isoquinolinediol (DHIQ; Santa Cruz Biotechnology), 3AB (Sigma), DR2313 (Wako Chemical), and UPF1069 (Wako Chemical) were used as PARP inhibitors. 


\section{Immunocytochemistry}

NSPCs were seeded at $5.0 \times 10^{4}$ cells per well in 8-well poly-L-ornithine- and fibronectin-coated Lab-Tek II Chamber Slides (Nalge Nunc). They were incubated for 6 days with or without $20 \mu \mathrm{M}$ PJ34 and the medium was changed every other day. Conversely, cells for the positive controls of neurons, astrocytes, and oligodendrocytes were incubated for 1 day in neural stem cell medium and then the medium was changed to $1 \times \mathrm{DMEM} / \mathrm{F}-12$ supplemented with B-27 for differentiation and incubated for 6 days. The cells were fixed in acetone/methanol for $2 \mathrm{~min}$. The antibodies to detect the following antigens were used for immunocytochemistry: nestin (sc-20978, 1:25; Santa Cruz Biotechnology or MAB353, 1:200; Chemicon), beta-III tubulin (MAB1195, 1:100; R\&D Systems), GFAP (Z0334, 1:500; Dako Cytomation), CNPase (MAB326, 1:200; Chemicon), p21 (sc-53870, 1:100; Santa Cruz Biotechnology), p53 (2524, 1:100; Cell Signaling), and phospho-p53 (Ser18) (9284, 1:50; Cell Signaling). Alexa Fluor dye-conjugated secondary antibodies of donkey anti-mouse IgG-Alexa Fluor 488 (A21202, 1:500; Molecular Probes) and goat anti-rabbit IgG-Alexa Fluor 568 (A11036, 1:500; Molecular Probes) were used for detection. Nuclear staining was performed using $1 \mathrm{nM} \mathrm{4}$, 6-diamidino-2-phenylindole (17514; ABD Bioquest). Cellular fluorescence images were acquired using a confocal laser scanning microscope (LSM 510; Carl Zeiss).

\section{MTS assay}

NSPCs were seeded at $1.0 \times 10^{4}$ cells per well in 96-well microplates coated with poly-L-ornithine and fibronectin. For 3-(4,5-dimethylthiazol-2-yl)-5-(3carboxymethoxyphenyl)-2-(4-sulfophenyl)-2H-tetrazolium, inner salt (MTS) assay, a CellTiter 96 AQueous One Solution Cell Proliferation Assay kit (Promega) was used following the manufacturer's instruction. Briefly, at $1 \mathrm{~h}$ before each of the desired time points, $20 \mu \mathrm{L}$ MTS reagent were added to each well and the cells were incubated at $37{ }^{\circ} \mathrm{C}$ for $1 \mathrm{~h}$. Absorbance was detected at $490 \mathrm{~nm}$ using a Microplate Reader (Model 680; Bio-Rad). All experiments were repeated 3 times.

\section{Gene expression profiling and data processing}

Total RNA was extracted from NSPCs with or without treatment with $20 \mu \mathrm{M}$ PJ34 by using an RNeasy Plus Mini Kit (QIAGEN). Microarray hybridizations were performed at Hokkaido System Science Co., Ltd. according to the manufacturer's protocol using the workflow for Agilent SurePrint G3 Mouse GE $(8 \times 60 \mathrm{~K})$ microarrays. Each total RNA was prepared independently twice and analyzed for 2 biological replicates. These data were deposited in the Gene Expression Omnibus (GEO) at NCBI (www.ncbi.nlm.nih.gov/geo/) (accession number
GSE69038). Differential expression analysis was performed using the limma package [33]. A linear model was fitted to each gene, and empirical Bayes moderated $t$-statistics were used to assess differences in expression. The false discovery rate (FDR) adjusted $p$ value was estimated using the Storey's $q$-value method [34], and statistical significance for differential expression was set to $q$ value $<0.05$ and $p$ value $<0.05$, coupled with a minimal difference of absolute fold change $>2$. Genes reaching statistical significance were mapped on pathways by using the Kyoto Encyclopedia of Genes and Genomes (KEGG) database [35]. The number of genes in each KEGG pathway category was counted using the KEGG Orthology (KO) identifier. Subsequently, significantly enriched KEGG pathway categories were extracted based on $p$ value $<0.0001$ and $q$ value $<0.01$ by Fisher's exact test, which was performed by using R (http://www.r-project. $\operatorname{org} /)$.

\section{Total RNA preparation and RT-PCR}

Cells rinsed with phosphate-buffered saline (PBS) were treated with a NucleoSpin RNA Plus Kit (MachereyNagel). Total RNA was isolated according to the manufacturer's protocol. RNA concentration was determined by measurement of $A_{260}$. cDNA was made from total RNA using a ReverTra Ace Kit (Toyobo) with $0.5 \mu \mathrm{g}$ total RNA per $25-\mu \mathrm{L}$ reaction following the manufacturer's instructions. Quantitative PCR for gene expression was performed with $2 \mu \mathrm{L}$ diluted cDNA using KAPA SYBR Fast qPCR Master Mix (KAPA Biosystems) with specific primers $(500 \mathrm{nM})$ in a total reaction volume of $5 \mu \mathrm{L}$. CFX96 Touch Real-time PCR System and CFX Manager software V3.1 (Bio-Rad Laboratories) were used to collect and analyze data. Three replicates of each sample were amplified. Relative quantitation of RNA levels was determined by comparative CT reactions $\left(\Delta \Delta \mathrm{C}_{\mathrm{T}}\right.$ analysis). Primers for the amplification of mouse Parp1, Parp2, and glyceraldehyde 3-phosphate dehydrogenase (Gapdh) (Table 1) were used. Gapdh served as the endogenous control. The quantity of target mRNA in each knockdown cell was expressed in arbitrary units (relative quantitation).

\section{Suppression of gene expression by shRNA}

Parp-knockdown (KD) and pLKO.1 empty vectors for short hairpin RNA (shRNA)-expressing lentivirus were purchased from Open Biosystems. The RNAi consortium (TRC) numbers were as follows: TRCN0000071211 (Parp1-KD) and TRCN0000071216 (Parp2-KD). Lentivirus was produced by transient transfection of 293T cells using a Trans-Lentiviral shRNA Packaging Kit (Thermo Fisher Scientific). The virus supernatant was concentrated by using a Lenti- $\mathrm{X}^{\mathrm{TM}}$ Concentrator (Takara Bio). 
Table 1 Primer sequences for RT-PCR gene expression analysis

\begin{tabular}{|c|c|c|c|c|}
\hline Gene & Sense primer $\left(5^{\prime}-3^{\prime}\right)$ & Anti-sense primer $\left(5^{\prime}-3^{\prime}\right)$ & Cycles & Product (bp) \\
\hline Parp1 & TCGATGGGAAAGTCCCACAC & CATTCTGAGCCTTGAGGGCC & 28 & 600 \\
\hline Parp2 & GACAATCGAGACTCTGTGAA & AGACTGGTAACCGGCCTTGA & 28 & 600 \\
\hline Gapdh & ACCACAGTCCATGCCATCAC & TCCACCACCCTGTTGCTGTA & 28 & 452 \\
\hline Cdknia & GTGATTGCGATGCGCTCATG & TCTCTTGCAGAAGACCAATC & 26 & 387 \\
\hline Fas & ATGCTGTGGATCTGGGCTGT & GTTTTCAGGTTGGCATGGTT & 28 & 190 \\
\hline Pidd & ATGGCTGCAGTGTTGGAGGG & CTCTGAGAGATGGTTGTGAG & 28 & 500 \\
\hline Tnfrsfiob & ATGGAGCCTCCAGGACCCAG & GAGCTCCAATCAGCAGCACT & 28 & 643 \\
\hline Pmaip1 & ATGCCCGGGAGAAAGGCGCG & GGTTACTAAATTGAAGAGCT & 28 & 308 \\
\hline$B b c 3$ & CCTCAGCCCTCCCTGTCACCAG & GGGTGAGGGTCGGTGTCGAT & 35 & 232 \\
\hline Perp & ATGCTGCGCTGCGGCCTGGC & GGAACAACCAATCAAGATGA & 28 & 500 \\
\hline Ccng1 & ATGATAGAAGTACTGACAAC & GGTGTCGTGAACGAGTGAAT & 24 & 500 \\
\hline $\operatorname{Trp53}$ & GGAGACATTTTCAGGCTTATGG & AGAAGGGACAAAAGATGACAGG & 28 & 232 \\
\hline
\end{tabular}

For virus infection, NSPCs were incubated with the concentrated virus supernatant in a 6 -well plate and centrifuged at $1200 \times g$ for $1 \mathrm{~h}$ at $32{ }^{\circ} \mathrm{C}$. The virus medium was removed at $6 \mathrm{~h}$ after infection and replaced with fresh medium. The infected cells were selected with $800 \mathrm{ng} /$ $\mathrm{mL}$ puromycin at 2 days after infection. Incubation was continued for an additional 2 days. Silencing was then assessed by measuring the levels of Parp1 and Parp2 mRNA using RT-PCR.

\section{Western blot analysis}

NSPCs $\left(2.0 \times 10^{6}\right.$ cells $)$ were seeded in $100-\mathrm{mm}$ dishes containing the PARP inhibitors or vehicle for $24 \mathrm{~h}$. Scraped cells were collected and added to a sample buffer solution containing 2-mercaptoethanol $(2 \times)$ for SDS-PAGE (Nacalai Tesque) and incubated at $95{ }^{\circ} \mathrm{C}$ for $5 \mathrm{~min}$. Proteins were separated using Mini-PROTEAN TGX gels (Bio-Rad), transferred with the Trans-Blot Turbo system (Bio-Rad), and detected with antibodies against the following proteins: beta-actin (A1978, 1:100,000; Sigma), p21 (sc-53870, 1:1000; Santa Cruz Biotechnology), p53 (2524, 1:10,000; Cell Signaling), phospho-p53 (Ser18) (9284, 1:1000; Cell Signaling), cleaved caspase-3 (Asp175) (9661, 1:1000; Cell Signaling), cleaved caspase-8 (Asp387) (9429, 1:1000; Cell Signaling), caspase-9 (9504, 1:1000; Cell Signaling), poly(ADP-ribose) (4336-BPC-100, 1:5000; Trevigen), PARP-1 (MCA1522G, 1:5000; Serotec), ataxia telangiectasia mutated (ATM) (ab2618, 1:5000; Abcam), and ataxia telangiectasia and Rad3-related (ATR) (sc-1887, 1:5000; Santa Cruz Biotechnology). A peroxidase-linked secondary antibody (NA931V, 1:1000; GE Healthcare) was used for detection. Antibody-antigen complexes were visualized by ImmunoStar LD (Wako). The chemiluminescent blots were imaged with a ChemiDoc XRS + imager (Bio-Rad) and analyzed by ImageLab software version
2.0.1 (Bio-Rad). All antibodies were distilled in HIKARI signal enhancer (Nacalai Tesque). For caspase activation, as a positive control, the cells were treated with $10 \mathrm{ng} /$ $\mathrm{mL}$ cycloheximide (Cell Signaling) for $24 \mathrm{~h}$ and $50 \mathrm{ng} / \mathrm{mL}$ mouse tumor necrosis factor- $\alpha$ (Cell Signaling) for $6 \mathrm{~h}$.

\section{Cell cycle analysis}

The cells were synchronized by the double-thymidineblock method as described previously, with minor modifications [36, 37]. $2.0 \times 10^{6}$ cells were seeded in twenty five $100 \mathrm{~mm}$ plates. One plate was used for time 0 (pretreatment). One set of 12 plates was used for PJ34 treatment, and another set of 12 plates was used for control. They were subjected to the first treatment with $2 \mathrm{mM}$ thymidine (Sigma) for $14 \mathrm{~h}$, and then incubated in thymidine-free medium for $12 \mathrm{~h}$, followed by the second treatment with $2 \mathrm{mM}$ thymidine for $14 \mathrm{~h}$ to arrest the cell cycle at the G1/S boundary. The cells were washed twice with $1 \times$ DMEM/F-12 and then incubated in neurosphere medium and analyzed every $2 \mathrm{~h}$. The nuclei of the treated cells were collected and stained with propidium iodide using a Cell Cycle TEST-PLUS DNA Staining Kit according to the manufacturer's instructions (Becton-Dickinson). The DNA content of the stained nuclei was measured using a FACSCalibur Flow Cytometer (Becton-Dickinson). The results were analyzed by using ModFit LT 3.0 software (Verity Software House).

\section{Flow cytometric analysis of cell death}

After incubation with $20 \mu \mathrm{M}$ PJ34 for $24 \mathrm{~h}$, the cells were collected by low-speed centrifugation, washed with icecold PBS, and resuspended in Annexin-V Binding Buffer (Becton-Dickinson). To detect Annexin-V-positive cells, the cells were incubated with Annexin-V (Becton-Dickinson) and 7-AAD (Becton-Dickinson) for $15 \mathrm{~min}$ at 
room temperature. The cells were analyzed with a FACSCalibur Flow Cytometer (Becton-Dickinson).

\section{Chromatin staining for the detection of apoptosis}

NSPCs were incubated with or without the PARP inhibitors on poly-L-ornithine/fibronectin-coated Lab-Tek II Chamber Slides (Nalge Nunc) for $24 \mathrm{~h}$. The cells were fixed with $4 \%$ paraformaldehyde in PBS for $10 \mathrm{~min}$, followed by chromatin staining with $1 \mu \mathrm{g} / \mathrm{mL}$ Hoechst 33258 (Sigma) to detect morphological changes of nuclei associated with apoptosis.

\section{Precipitation of poly(ADP-ribosyl)ated proteins}

Poly(ADP-ribosyl)ated proteins were isolated by using a highly specific Af1521 Macrodomain Poly(ADP-ribose) Affinity Resin Set (Tulip Biolabs). NSPCs were incubated with or without $20 \mu \mathrm{M}$ PJ34 for $24 \mathrm{~h}$. Proteins were extracted from $4.0 \times 10^{6}$ cells using a lysis buffer (RIPA Buffer; Nacalai Tesque) and incubated with the affinity resin overnight at $4{ }^{\circ} \mathrm{C}$. The resin-bound proteins were dissociated from the affinity resin by incubation in SDS-sample buffer at $95{ }^{\circ} \mathrm{C}$ for $10 \mathrm{~min}$ and analyzed by immunoblotting.

\section{Immunoprecipitation}

NSPCs were incubated with or without $20 \mu \mathrm{M}$ PJ34 for $24 \mathrm{~h}$. Cell lysates were prepared from $4.0 \times 10^{6}$ cells using RIPA buffer (Nacalai Tesque). An antibody against p53 (2524, 1:500; Cell Signaling), ATM (ab2618, 1:500; Abcam), or ATR (sc-1887, 1:500; Santa Cruz Biotechnology) was added to the cell lysates, and $\mu$ MACS Protein A/G MicroBeads (Miltenyi Biotec) were added to magnetically label the immune complexes. Magnetically labeled proteins were collected by using $\mu$ Columns and $\mathrm{MACS}$ Separator (Miltenyi Biotec), and analyzed by immunoblotting.

\section{Statistical analysis}

The data were expressed as the mean value \pm standard error of the mean (SEM). We used one-way ANOVA followed by Tukey's post hoc test to analyze the differences among the three or more groups, and used Student's $t$ test for the differences between the two groups. Results were considered statistically significant at $p<0.05$.

\section{Results}

Suppression of neurosphere formation by PARP inhibitors NSPCs from the mouse brain were incubated with or without the PARP inhibitors (3AB, DHIQ, or PJ34). Neurospheres were generated in the absence of the PARP inhibitors after incubation for 2 days, while neurosphere formation was suppressed by the PARP inhibitors in a concentration-dependent manner. Neurospheres were almost absent with $15 \mathrm{mM} 3 \mathrm{AB}, 200 \mu \mathrm{M}$ DHIQ, or $20 \mu \mathrm{M}$ PJ34 (Fig. 1a). The concentrations of the 3 inhibitors required for these biological effects on NSPCs corresponded to their half maximal (50\%) inhibitory concentrations (IC50s): IC50s of $3 \mathrm{AB}, \mathrm{DHIQ}$, and PJ34 were $33 \mu \mathrm{M}, 390 \mathrm{nM}$, and $20 \mathrm{nM}$, respectively [38, 39]. An approximately 1000-fold higher concentration of the inhibitors, as compared with their IC50s, effectively suppressed neurosphere formation by NSPCs. We then evaluated the viability of NSPCs by measuring MTS-reducing activity, which was increased by 2.6-fold after culture for 2 days in the absence of the PARP inhibitors (Fig. 1b). This increase was significantly suppressed by the addition of the PARP inhibitors (3AB, DHIQ, or PJ34), indicating that exposure to the PARP inhibitors damages the viability of NSPCs.

\section{No induction of NSPC differentiation by a PARP inhibitor}

While the PARP inhibitors suppressed NSPC neurosphere formation, a small population of NSPCs attached to the bottom of the culture dish and extended projections, suggesting their differentiation into neurons or glial cells (Fig. 2a). We examined the phenotype of these cells by immunostaining for several cell type-specific markers: nestin for NSPCs, Tuj-1 for neurons, GFAP for astrocytes, and CNPase for oligodendrocytes. Tuj-1 or CNPase was undetectable after incubation with or without PJ34 for 6 days, indicating no differentiation into neurons or oligodendrocytes, respectively, by this PARP inhibitor. Conversely, GFAP was detectable in a subpopulation of NSPCs both in the presence and absence of PJ34, indicating that NSPCs could be differentiated into astrocytes under the present experimental conditions regardless of their exposure to this PARP inhibitor. The ratio of nestin-positive cells appeared not to be changed by PJ34, suggesting no effects of this PARP inhibitor on NSPC differentiation. These morphological changes were supported by quantitative mRNA analysis of cell type-specific markers (Fig. 2b). Among these markers, GFAP was only upregulated by a few fold after the addition of $20 \mu \mathrm{M}$ PJ34. Conversely, the expression of GFAP increased by more than 600 -fold after in vitro differentiation of NSPCs into astrocytes. Most of the cells stopped proliferating and became apoptotic, while only a small number of cells, which attached to the bottom of the dishes, morphologically changed and extended projections. It appears that the cells that attached, or survived, differentiated into astrocytes, which likely caused a weak but significant upregulation of GFAP mRNA.

\section{Suppression of cell cycle progression by a PARP inhibitor} We then assessed cell cycle progression in NSPCs by thymidine incorporation. $S$ phase cells were obtained by using a double thymidine block that arrests the cells at 
a
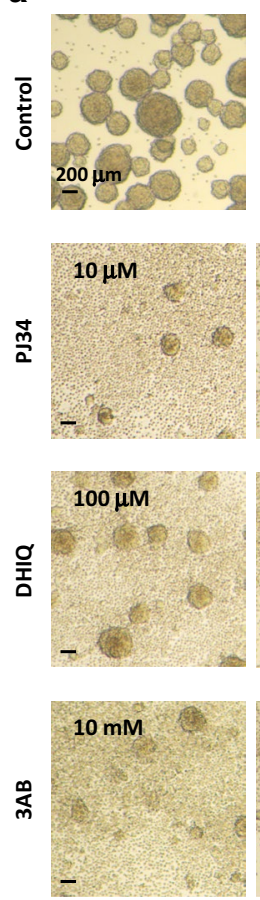
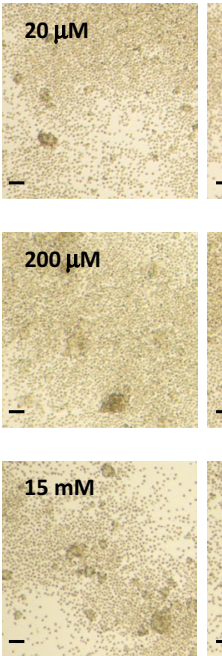

b

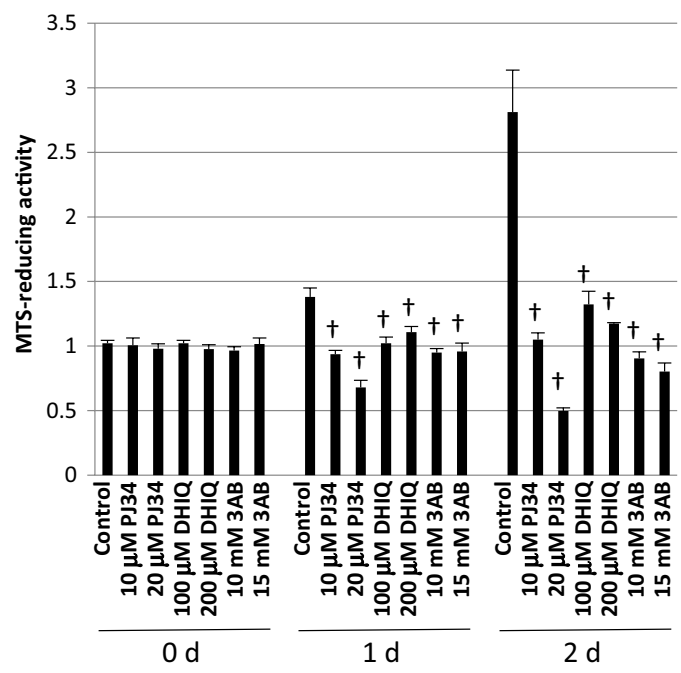

Fig. 1 Suppression of neurosphere formation and cell viability of NSPCs by PARP inhibitors. a Multiple neurospheres were detectable after a 2-day incubation of NSPCs without a PARP inhibitor (control), while the number and size of neurospheres were much smaller in the presence of a PARP inhibitor (PJ34, DHIQ, or 3AB) in a dose-dependent manner. b Cell viability was determined by the MTS assay. The MTS-reduction activity of NSPCS was suppressed by the addition of a PARP inhibitor. Data shown in (b) are expressed as the ratio of the mean value of the control (vehicle alone) at time 0 (before incubation). Data represent the mean value $\pm \operatorname{SEM}(n=3) .{ }^{+} p<0.01$ by comparison against control using one-way ANOVA followed by Tukey's post hoc test

the G1/S boundary. The removal of thymidine by replacement with normal medium, with or without the PARP inhibitor PJ34, induced the onset of the S phase. Every $2 \mathrm{~h}$ from the onset of DNA synthesis, the cell cycle was analyzed by flow cytometry (Fig. 3). The proportion of cells in the G2/M phase reached the maximum value at $6 \mathrm{~h}$ from the onset of the $\mathrm{S}$ phase in the absence of PJ34, while it took $8 \mathrm{~h}$ in the presence of PJ34. The peak of the proportion of cells in the G1 phase occurred after 14 or $10 \mathrm{~h}$ with or without PJ34, respectively. These results suggest that treatment with PJ34 suppressed cell cycle progression in NSPCs at the S phase and/or G2/M phase.

\section{Induction of apoptosis in NSPCs by PARP inhibitors}

The suppression of cell viability led us to examine whether the PARP inhibitors induce cell death, either necrosis or apoptosis, in NSPCs. Nuclear staining with Hoechst 33258 showed an intact or chromatin-condensed apoptotic pattern. Apoptotic cells prevailed after exposure to the PARP inhibitors (PJ34, DHIQ, or 3AB) in a concentration-dependent manner (Fig. 4a).

The pattern of cell death was then analyzed by the use of flow cytometry with APC-conjugated Annexin-V and
7-AAD. Annexin- $V$ has high affinity for phosphatidylserine that is translocated from the inner to the outer leaflet of the plasma membrane during apoptosis. The cell membrane of live cells is impenetrable to 7-AAD, but 7-AAD readily permeates and stains dead cells. Annexin- $\mathrm{V}(+) / 7-$ $\mathrm{AAD}(-)$ cells were considered to be at the early stage of apoptosis, whereas Annexin- $\mathrm{V}(+) / 7-\mathrm{AAD}(+)$ cells could be either necrotic or apoptotic at a later stage. Treatment with PJ34 significantly increased the proportion of apoptotic Annexin- $\mathrm{V}(+) / 7-\mathrm{AAD}(-)$ cells by $27 \%$ compared to $12 \%$ in the control cells and decreased that of intact Annexin-V(-)/7-AAD(-) cells by $71 \%$ compared to $87 \%$ in the control cells (Fig. 4b).

\section{Changes of mRNA expression profiles in the $\mathrm{p} 53$ signaling pathway by PARP inhibitors}

In order to identify the causative genes that are involved in the pathway leading to the suppression of cell cycle progression and induction of apoptosis, microarray analyses were carried out. The mRNA expression profiles in NSPCs were compared between cells in the presence and absence of PJ34. We found 142 genes upregulated and 83 genes downregulated by PJ34 with more than 
a

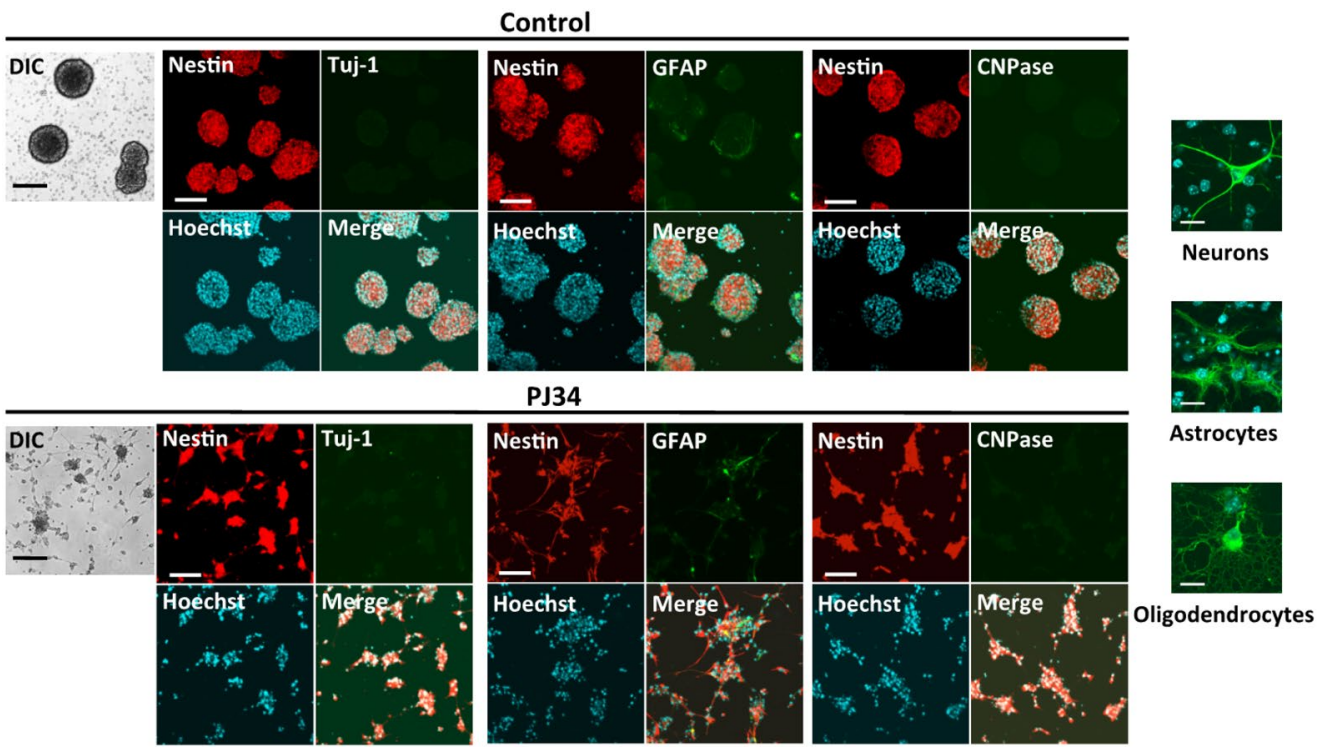

b

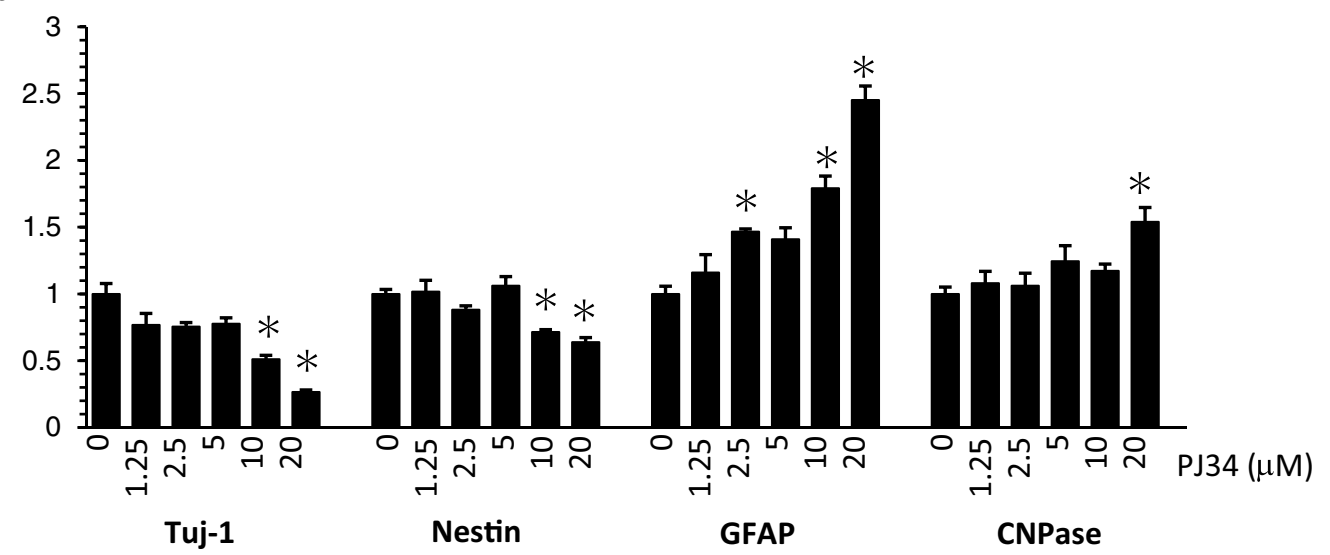

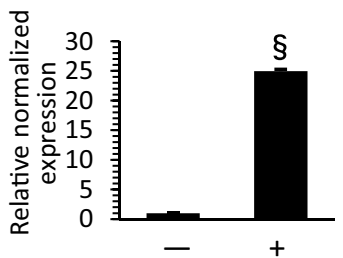

Tuj-1

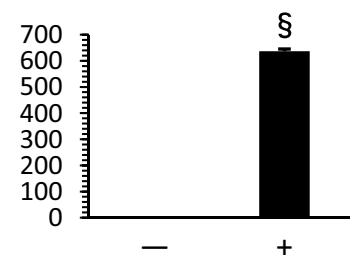

GFAP
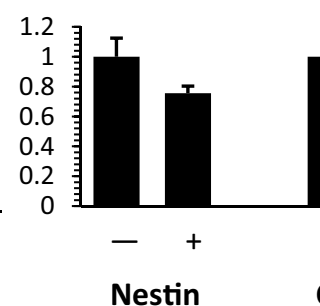

Fig. 2 No induction of differentiation of NSPCs into neurons or glial cells by a PARP inhibitor. a The cells were triple-stained with Hoechst 33258 (nuclear staining), anti-nestin antibody (for NSPCs), and a cell-specific antibody: anti-Tuj-1 antibody (for neurons), anti-GFAP antibody (for astrocytes), or anti-CNPase antibody (for oligodendrocytes). Although the morphology of NSPCs was changed considerably after the addition of PJ34, the pattern of immunostaining was not changed. Differential interference contrast (DIC) images were on the left side. The positive controls for the antibodies used here are shown in the small images. b Quantitative mRNA analyses at $24 \mathrm{~h}$ after the addition of PJ34 (shown in the upper row) or 6 days after withdrawal of the growth factors EGF and FGF for differentiation into astrocytes (shown in the lower row) were performed for cell typespecific markers: Tuj-1 for neurons, nestin for NSPCs, GFAP for astrocytes, and CNPase for oligodendrocytes. Among these markers, GFAP was only upregulated by a few fold after the addition of $20 \mu \mathrm{M}$ PJ34, while the expression of GFAP increased by more than 600-fold after in vitro differentiation of NSPCs into astrocytes. Data shown in (b) are expressed as the ratio of the mean value of the control (vehicle alone). Data represent the mean value \pm SEM $(n=3) .^{*} p<0.05$ (in the upper row) by comparison against control using one-way ANOVA followed by Tukey's post hoc test. ${ }^{\dagger} p<0.01$

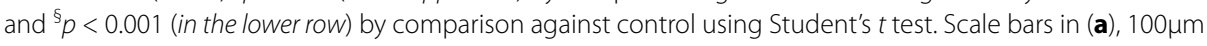



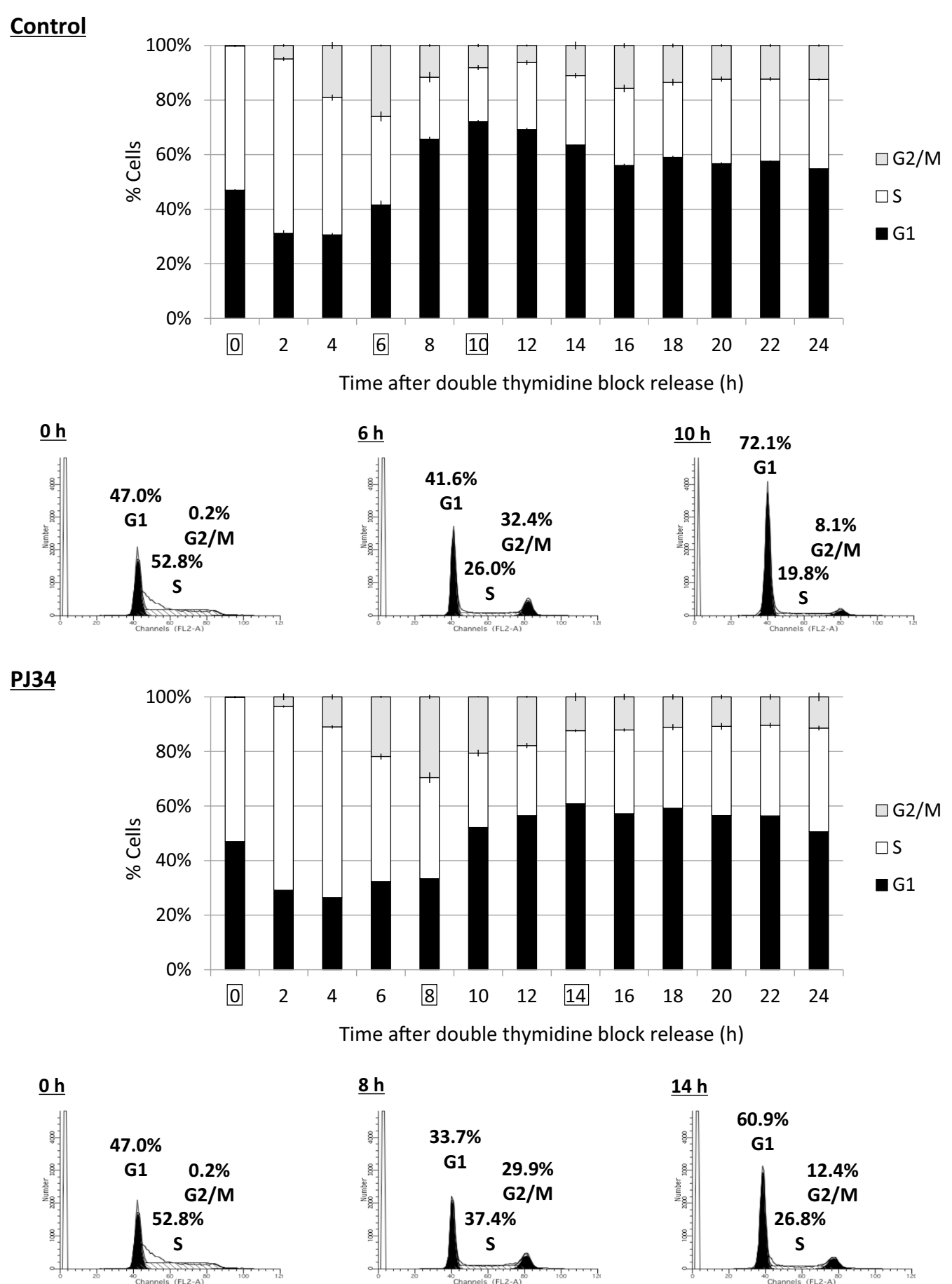

Fig. 3 Suppression of cell cycle progression of NSPCs by PJ34. Progression of the cell cycle with or without PJ34 was analyzed by thymidine incorporation, followed by flow cytometry. The ratios of cells in the G1, S, and G2/M phases are illustrated every $2 \mathrm{~h}$ after the onset of the $\mathrm{S}$ phase. The results of flow cytometry at the peak of the G2/M or G1 phase are shown. Data represent the mean value $\pm \operatorname{SEM}(n=3)$

a twofold change $(p<0.05)$. In addition, several genes related to the p53 signaling pathway were significantly upregulated after the addition of PJ34, as shown by differential expression analysis $(p$ value $=2.02 \mathrm{E}-8$ and $q$ value $=8.48 \mathrm{E}-7)($ Table 2 ; Fig. $5 \mathrm{a})$. The upregulation of Cdkn1a (p21), which plays a critical role in the control of the cell cycle, was more than twofold in the two analyses performed. Several genes in the pathway 
a
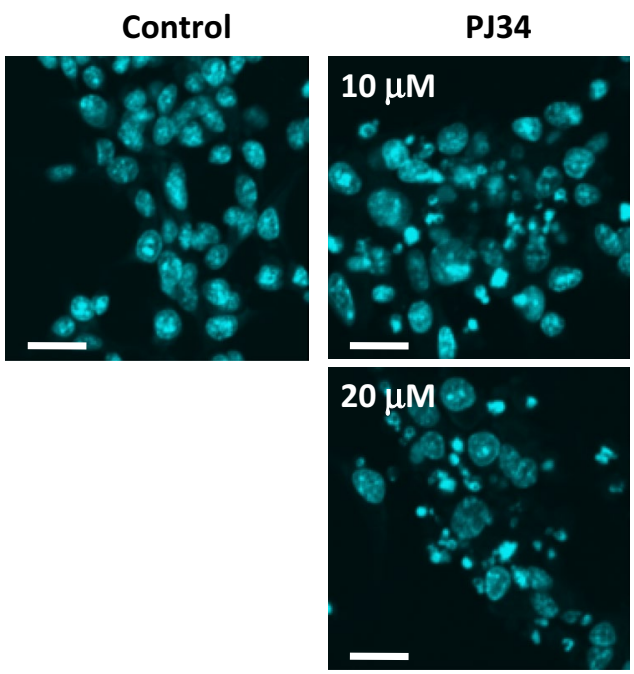

PJ34
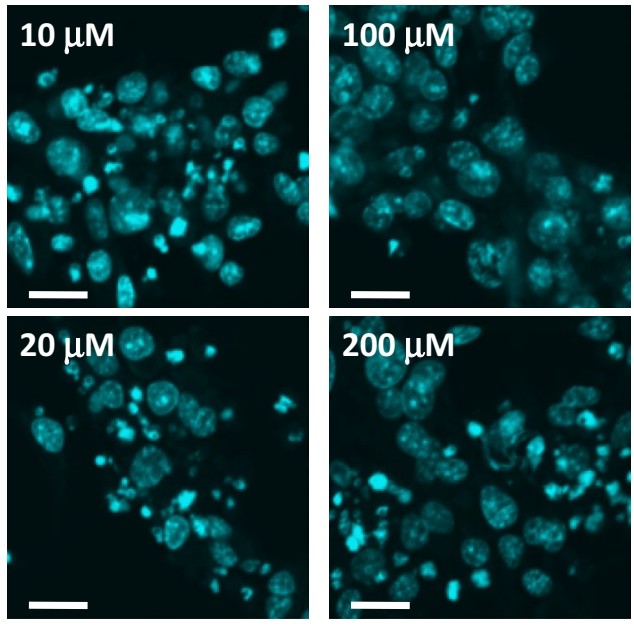

DHIQ

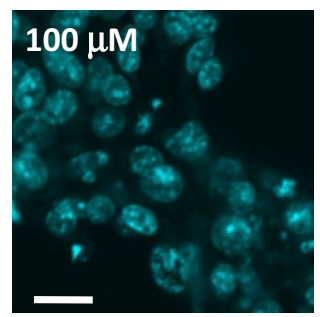

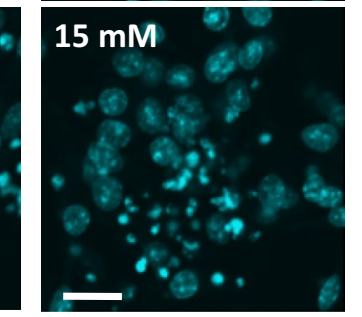

b

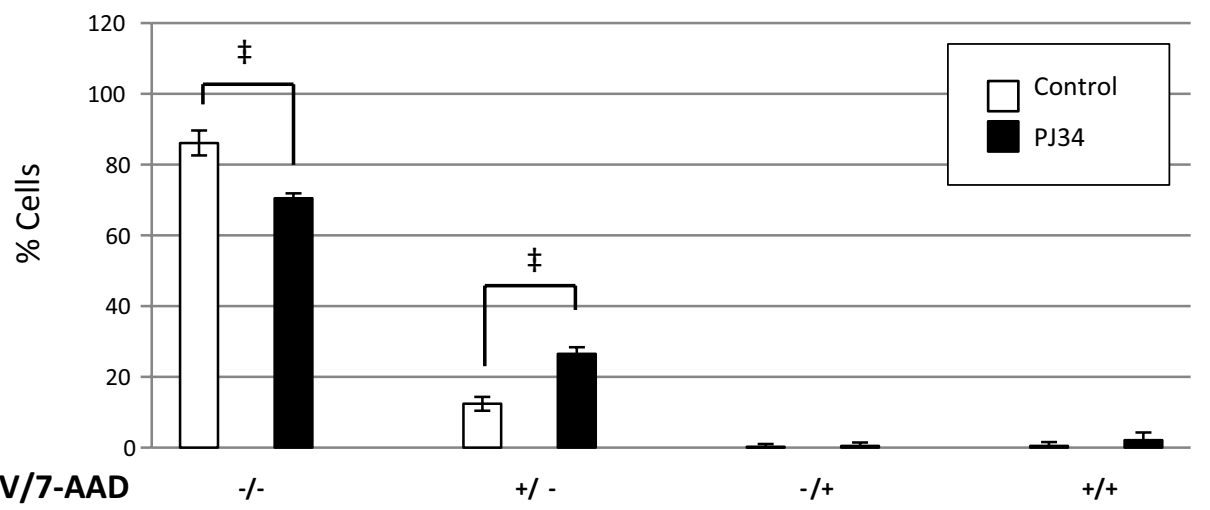

Fig. 4 Induction of apoptosis in NSPCs by PARP inhibitors. a NSPCs were stained with Hoechst 33258 after a 24-h incubation with the PARP inhibitors. Cells with condensed chromatin, which is indicative of apoptosis, were detectable after the addition of PJ34, DHIQ, or 3AB. The ratio of apoptotic cells increased in a dose-dependent manner. $\mathbf{b}$ The rate of Annexin-V-positive cells after the addition of $20 \mu \mathrm{M}$ PJ34 was analyzed by the use of flow cytometry staining with APC-conjugated Annexin-V and 7-AAD. Data represent the mean value \pm SEM $(n=6) .{ }^{\ddagger} p<0.005$ by comparison against control using Student's $t$ test. Scale bars in (a), 20 $\mu \mathrm{m}$

leading to apoptosis, including Fas (Fas), Pidd (PIDD; p53-induced death domain protein), Pmaip1 (Noxa), and Bbc3 (PUMA; p53 upregulated modulator of apoptosis), were also upregulated by more than 2-fold. Furthermore, Ccng1 (cyclin G1), which is involved in p53 negative feedback, was also upregulated. These results from the microarray analyses were confirmed by RT-PCR (Fig. 5b), indicating that PJ34 and also the other PARP inhibitors, DHIQ and $3 \mathrm{AB}$, activate the two pathways downstream of p53: one pathway leads to cell cycle arrest through the activation of $\mathrm{p} 21$, while the other induces apoptosis by some apoptosis-related factors. Interestingly, the RT-PCR results demonstrated that the amount of $p 53$ mRNA in NSPCs was not changed by the PARP inhibitors, whereas p53 protein was increased by the PARP inhibitors (Fig. 5c). This inconsistency indicated that the increase of p53 protein was not due to the overexpression of $\operatorname{Trp} 53$ (p53), but to the suppression of p53 protein degradation. In this context, the phosphorylation of p53 at Ser 18, which inhibits the binding of Mdm2 and stabilizes p53 protein, was found to be increased by the PARP inhibitors. The amount of $\mathrm{p} 21$ protein was definitely increased by the PARP inhibitors, which is consistent with the upregulation of p21 mRNA expression. Furthermore, activation of the p53 signaling pathway to apoptosis resulted in the cleavage of pro-caspase-3.

In order to clarify which member of the PARP family is responsible for these effects of PJ34 on NSPCs, we used quantitative mRNA analysis to evaluate the effects of the inhibitors DR2313 and UPF1069, which are specific for PARP-1 and PARP-2, respectively (Fig. 5d). DR2313 upregulated the genes in the p53 signaling pathway in a similar 
Table 2 Statistically significant changed categories (control vs. PJ34 in wild-type or Trp53-/-)

\begin{tabular}{|c|c|c|c|c|c|}
\hline Gene name & Product & Probe name & Fold change & $p$ value & $q$ value \\
\hline \multicolumn{6}{|c|}{142 genes were up-regulated by PJ34 in wild-type NSPCs } \\
\hline \multicolumn{6}{|c|}{ p53 signaling pathway } \\
\hline$B b c 3$ & PUMA (BCL2 binding component 3) & A_51_P248122 & 2.82 & 0.0136 & 0.0026 \\
\hline Ccng1 & Cyclin G1 & A_52_P612803 & 2.46 & 0.0240 & 0.0028 \\
\hline Cdkn1a & p21 (cyclin-dependent kinase inhibitor 1A) & A_51_P363947 & 2.99 & 0.0082 & 0.0023 \\
\hline Fas & Fas (TNF receptor superfamily member 6) & A_55_P2091676 & 3.50 & 0.0053 & 0.0018 \\
\hline Lrdd & PIDD (p53 induced death domain protein 1) & A_55_P2085485 & 2.24 & 0.0215 & 0.0028 \\
\hline Perp & PERP (p53 apoptosis effector) & A_51_P317941 & 5.03 & 0.0028 & 0.0016 \\
\hline Pmaip 1 & Noxa (phorbol-12-myristate-13-acetate-induced protein 1) & A_51_P477121 & 3.80 & 0.0144 & 0.0026 \\
\hline Tnfrsfiob & DR5 (tumor necrosis factor receptor superfamily, member 10b) & A_55_P2027836 & 3.23 & 0.0295 & 0.0029 \\
\hline \multicolumn{6}{|c|}{$\begin{array}{l}83 \text { genes were down-regulated by PJ34 in wild-type NSPCs } \\
\text { n/a }\end{array}$} \\
\hline \multicolumn{6}{|c|}{121 genes were up-regulated by PJ34 in Trp53-/- NSPCs } \\
\hline \multicolumn{6}{|c|}{166 genes were down-regulated by PJ34 in Trp53-/- NSPCs } \\
\hline
\end{tabular}

$\mathrm{n} / \mathrm{a}$ indicates all categories' $p$-values was more than $1 \mathrm{E}-04$

way as PJ34, while UPF1069 did not change the expression of these genes, except $B b c 3$ (PUMA). These findings confirmed PARP-1, but not PARP-2, as a target enzyme of PJ34 for its effects on the p53 signaling pathway in NSPCs.

\section{Effects of PARP-1 or PARP-2 knockdown on the p53 signaling pathway in NSPCs}

We then carried out silencing of Parp1 or Parp2 by infection with shRNA-expressing lentiviruses. Parp1 or Parp2 shRNA reduced the expression of the target gene to approximately $10 \%$ compared with control shRNA (Fig. 6a). Genes in the p53 signaling pathway were upregulated by the suppression of Parp 1 expression, but not by Parp 2 suppression (Fig. 6b). These findings were consistent with those obtained in the inhibitor experiments, and indicate that PARP-1, but not PARP-2, regulates the functions of p53 in NSPCs.

\section{Activation of p53 by PARP inhibitors}

The induction of apoptosis by the PARP inhibitors was demonstrated again by the detection of cleaved caspase fragments (Fig. 7a). One of the effector caspases, caspase-3, was activated, as revealed by the detection of the cleaved fragment (p17) of pro-caspase-3. Among the initiator caspases, caspase- 8 and caspase- 9 were also demonstrated to be activated by the detection of the cleaved fragments of the pro-caspases $\mathrm{p} 43 / \mathrm{p} 41 / \mathrm{p} 18$ and $\mathrm{p} 37$, respectively, although the band density of p37 was low.

The increased amount of total p53 and its phosphorylated form after the addition of PJ34 was revealed by immunostaining with antibodies against p53 and phosphorylated p53 (Ser18), respectively (Fig. 7b). Furthermore, NSPCs contained much higher levels of PARP-1 protein than MEFs and this enzyme was constitutively activated, as revealed by its automodification, in NSPCs (Fig. 7c). The 89-kDa fragment of PARP-1, which is generated by its cleavage by activated caspase-3, was also detectable. The increase of p53 protein and its phosphorylation in the presence of PJ34 were observed in NSPCs, but not in MEFs.

Effects of a PARP inhibitor on Trp53 $3^{+/-}$and Trp53 $53^{-/-}$NSPCs In order to confirm a key role for $\mathrm{p} 53$ in the process under the regulation of poly(ADP-ribosyl)ation, we examined the effects of a PARP inhibitor on Trp53-1- as well as Trp $53^{+/-}$NSPCs. PARP inhibition by PJ34 increased both total and phosphorylated p53 levels in wild-type and Trp $53^{+/-}$NSPCs (Fig. 8a). Trp $53^{-1-}$ NSPCs formed larger neurospheres than $\operatorname{Tr} 553^{+/-}$NSPCs, while Trp $53^{+/-}$NSPCs generated a larger number of neurospheres than wild-type NSPCs (Fig. 8b). After incubation with $10 \mu \mathrm{M}$ or $20 \mu \mathrm{M}$ PJ34 for 2 days, only a few neurospheres were observed in wild-type NSPCs. In Trp $53^{+/-}$ NSPCs, neurospheres were still abundant in the presence of PJ34 at $10 \mu \mathrm{M}$, but not at $20 \mu \mathrm{M}$, although the neurospheres became smaller. Remarkably, even at a concentration of $20 \mu \mathrm{M}$, a substantial number of neurospheres were still present in Trp53 -/- NSPCs.

Cell viability was evaluated by measuring MTS-reducing activity. It should be noted that $\operatorname{Tr} p 53^{-1-}$ NSPCs showed higher activity than wild-type or Trp $53^{+/-}$NSPCs in the absence of PJ34 (Fig. 8c). After the addition of $10 \mu \mathrm{M}$ or $20 \mu \mathrm{M}$ PJ34, the MTS-reducing activity of wild-type NSPCs was decreased. PJ34 also decreased the 
a

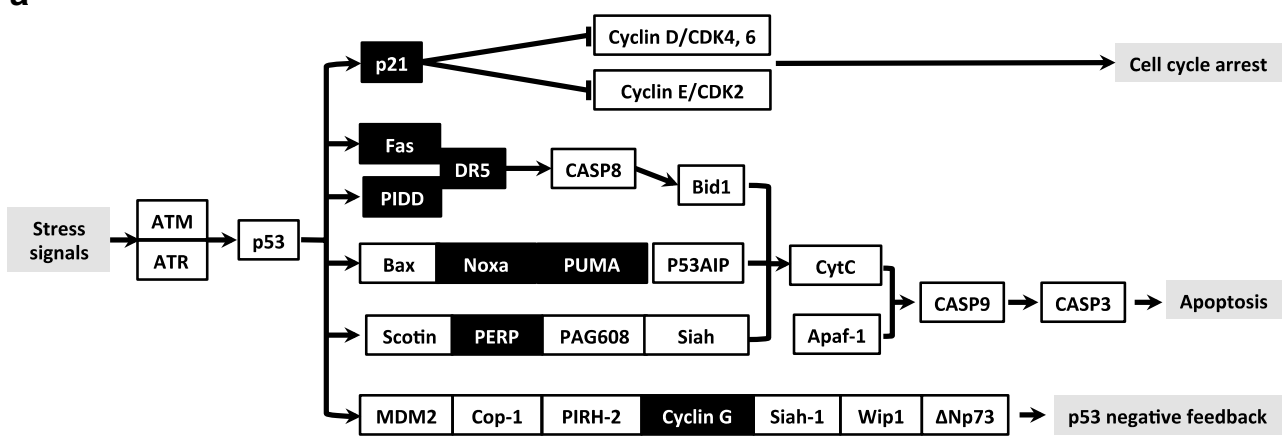

b

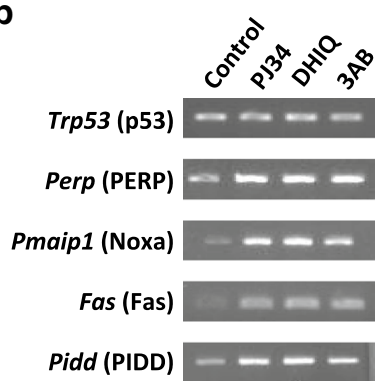

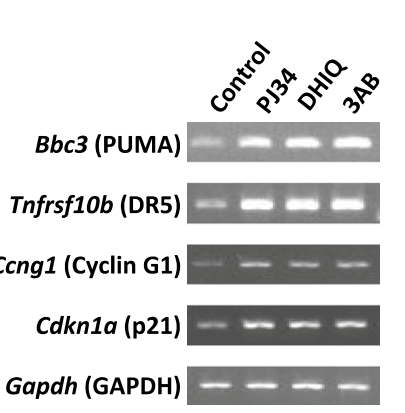

c

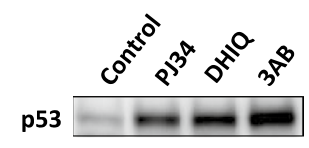

P-p53 (S18)

p21

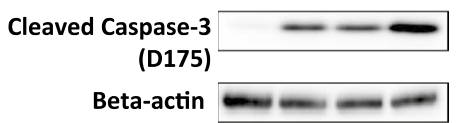

d
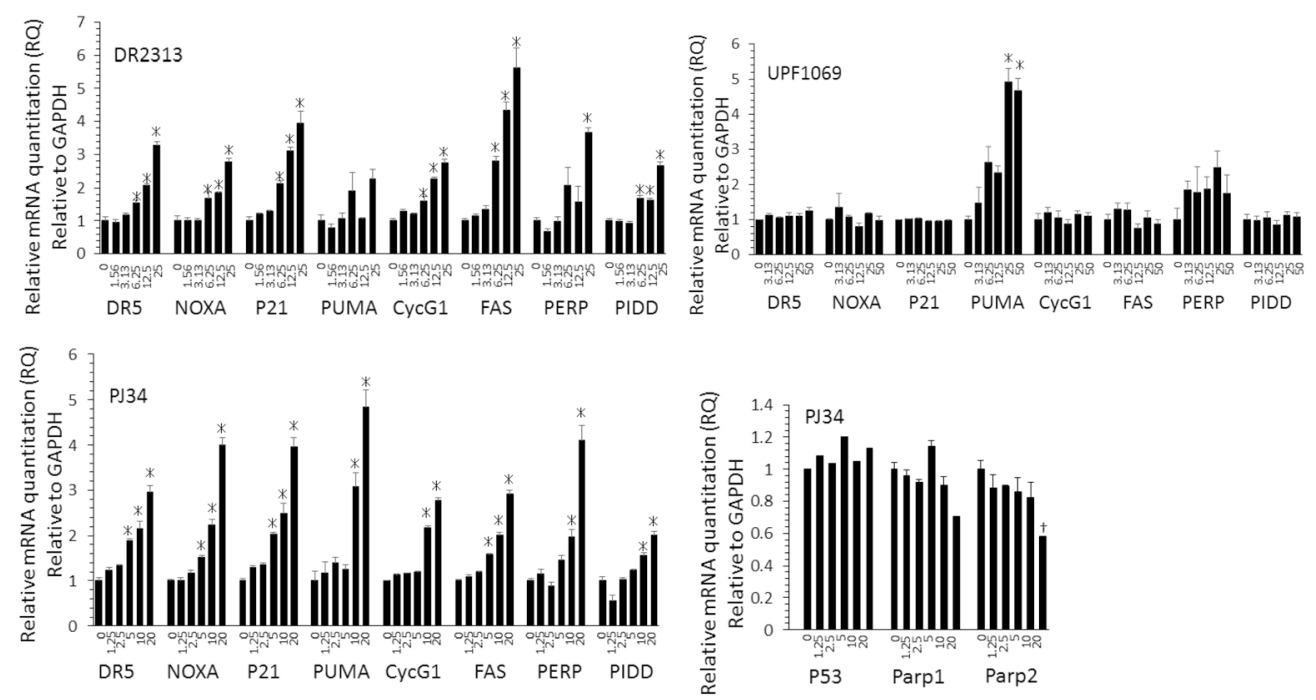

Fig. 5 Change of mRNA expression profiles in the p53 signaling pathway. a The mRNA expression profiles were generated by microarray analysis. The genes, the expression level of which increased more than 2-fold after PARP inhibition, are indicated as a black box in the p53 signaling pathway published by the KEGG database. b The mRNA expression profiles shown in (a) were confirmed by RT-PCR. Several genes downstream to Trp53 (p53) were upregulated after PARP inhibition, whereas Trp53 itself was constant regardless of the presence of the PARP inhibitors. c Changes in the levels of p53 and phosphorylated p53 by the PARP inhibitors (PJ34, DHIQ, or 3AB) were observed in NSPCs. p21 protein as well as p21 mRNA, as shown in (b), were upregulated by all of the PARP inhibitors. Cleaved fragment of caspase-3 at Asp 175 (p17), which is a marker of apoptosis, was also increased by PARP inhibition. d Quantitative mRNA analyses after the addition of PJ34, DR2313 (PARP-1-specific inhibitor), or UPF1069 (PARP2-specific inhibitor) were performed for the genes in the p53 signaling pathway. DR2313 as well as PJ34 upregulated the genes in the p53 signaling pathway, while UPF1069 did not change the expression of these genes, except Bbc3 (PUMA). Data shown in (d) are expressed as the ratio of the mean value of the control (vehicle alone). Data represent the mean value $\pm \operatorname{SEM}(n=3) .{ }^{*} p<0.05$ by comparison against control using one-way ANOVA followed by Tukey's post hoc test 


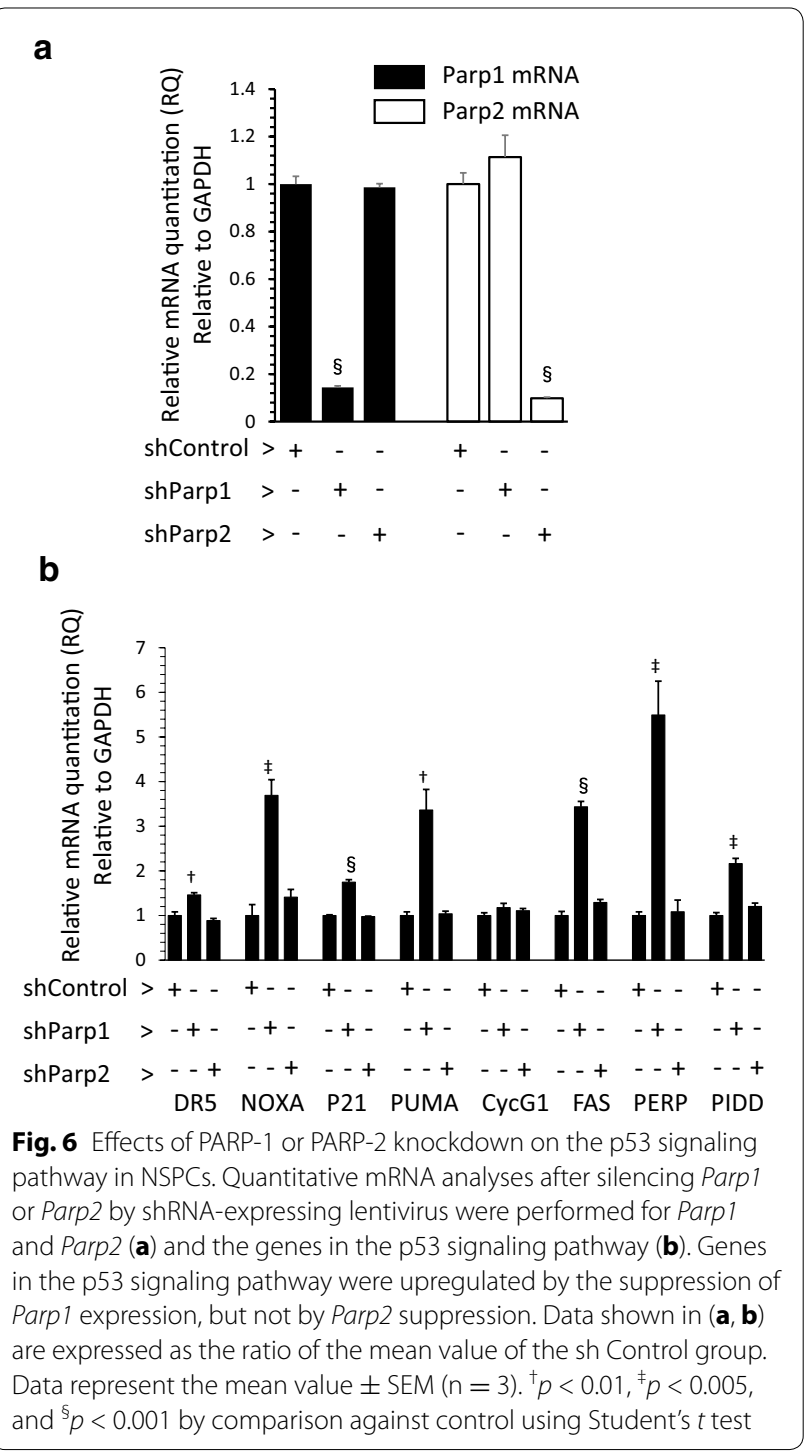

MTS-reducing activity of $\operatorname{Trp} 53^{+/-}$NSPCs at a concentration of $20 \mu \mathrm{M}$, but not $10 \mu \mathrm{M}$, whereas that of $\operatorname{Tr} p 53^{-1-}$ NSPCs was increased even after the addition of PJ34. These results clearly indicate that the effect of the PARP inhibitor PJ34 on the viability of NSPCs is mediated by p53.

In order to confirm the mRNA expression profiles in Trp $53^{-1-}$ NSPCs, mRNA levels were compared between the cells in the presence and absence of $20 \mu \mathrm{M}$ PJ34 by microarray analyses. 121 genes were upregulated by and 166 genes were downregulated by PJ34. However, there was no significantly changed category (Table 2 ).

\section{Poly(ADP-ribosyl)ation of ATM and ATR}

As demonstrated by the experiments using $\operatorname{Trp} 53^{-/-}$ NSPCs, p53 plays a key role in the regulation of cell viability by the PARP inhibitors. We then examined the molecular mechanism of p53 activation by the PARP inhibitors. We performed a pull-down assay using poly-ADP-ribose affinity resin, but were unable to isolate poly(ADP-ribosyl)ated p53 (Fig. 9a). An immunoprecipitation study using an antip53 antibody showed the increased quantity of p53 protein after exposure to the PARP inhibitor PJ34, while poly(ADPribosyl)ation of $\mathrm{p} 53$ was undetectable.

As both ATM and ATR regulate the stability and activation of p53 by phosphorylation at Ser18 [40], we examined whether PARP inhibition affects these 2 serine/ threonine protein kinases. We performed a pull-down assay with poly-ADP-ribose affinity resin, and detected both ATM and ATR at their expected sizes using specific antibodies (Fig. 9b). Certainly, the addition of PJ34 inhibited the isolation of both kinases by poly-ADPribose affinity resin. Poly(ADP-ribosyl)ation of these two kinases was confirmed by immunoprecipitation with an anti-ATM or anti-ATR antibody followed by detection with an anti-poly(ADP-ribose) antibody (Fig. 9c). Together with the finding of PARP-1 activation in NSPCs (see Fig. 9c), both ATM and ATR were found to be constitutively poly(ADP-ribosyl)ated in these cells.

\section{Discussion}

NSPCs are localized in specific areas in the adult brain such as the subgranular zone of the dentate gyrus of the hippocampus and subventricular area of the lateral ventricles $[13,14]$. Once the brain is damaged by ischemia, NSPCs are activated and move to the infarct area [16]. Previously, we reported that PARP inhibitors could be a good therapeutic intervention for ischemic brain disorders through inhibition of apoptosis as well as necrosis of the affected neurons [9]. Lacza et al. [41] reported an improvement of the effectiveness of neural stem cell transplantation through the suppression of the $\mathrm{ONOO}^{-}-\mathrm{PARP}$ activation cascade by PARP inhibitor. However, administration of PARP inhibitors might influence NSPCs in the brain. In the present study, we demonstrated two types of effects of PARP inhibitors on NSPCs: suppression of cell cycle progression and induction of apoptosis. From a therapeutic point of view, these effects should be taken into consideration to determine the appropriate doses of PARP inhibitors.

The key molecule underlying these effects of the PARP inhibitors was proven to be $\mathrm{p} 53$, which restricts cellular growth by inducing cell cycle arrest (at the G1 and/or G2 phase) or apoptosis $[42,43]$. Several factors that influence the decision between the two types of effect include the expression level of p53, the type of stress signal, and cell type. Under our experimental conditions for NSPCs, where the cells were not exposed to specific stresses, the expression level of p53 was consistent and its phosphorylation, or activation, was suppressed. After the addition of the PARP 


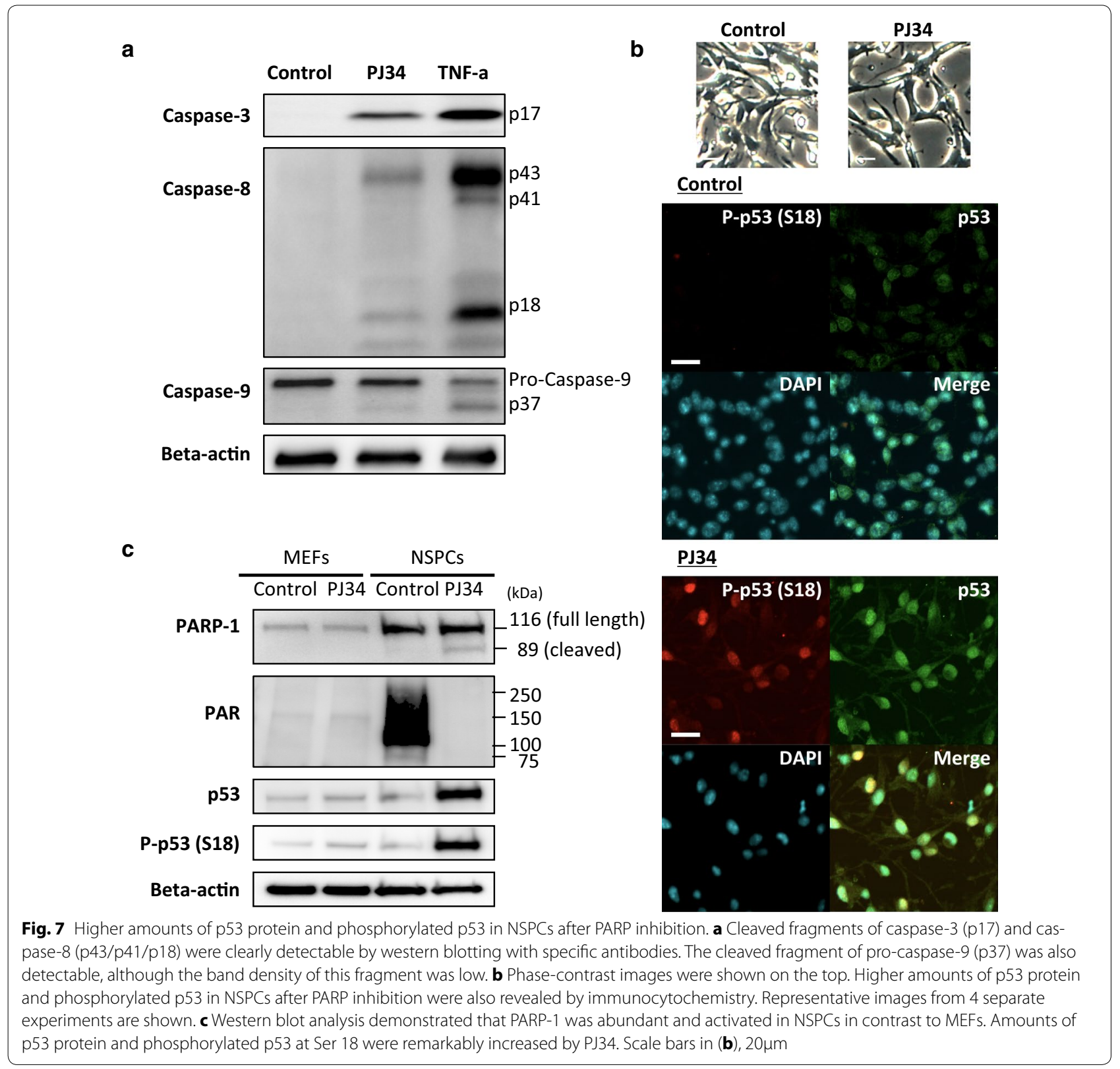

inhibitors, phosphorylation of p53 at Ser18 was enhanced, followed by the upregulation of $\mathrm{p} 21$, which is a potent cyclin-dependent kinase inhibitor that functions as a regulator of cell cycle progression at the $\mathrm{G} 1$ and S phase [44].

The PARP inhibitor PJ34 also upregulated other p53-dependent factors in the pathways to apoptosis, i.e., Fas, PIDD, DR5, and PERP in the extrinsic apoptotic pathway and Noxa and PUMA in the intrinsic apoptotic pathway [45]. The extrinsic pathway is mediated by particular death receptors that are members of the tumor necrosis factor receptor family, including Fas, DR5, and PERP, whose activation induces the formation of the death-inducing-signaling-complex, and then activation of the caspase cascade, including caspase- 8 and caspase-3. In our study, both caspases were definitely activated after PARP inhibition, as revealed by the detection of the cleaved fragments of pro-caspases.

The intrinsic apoptotic pathway is activated in response to DNA damage and results in mitochondrial depolarization and release of cytochrome $\mathrm{c}$ into the cytoplasm [45]. Cytochrome c forms a complex "apoptosome" together with apoptotic protease-activating factor 1 and pro-caspase- 9 , followed by the activation of caspase- 9 and then activation of other caspases such as caspase- $-3,-6$, and -7 
a
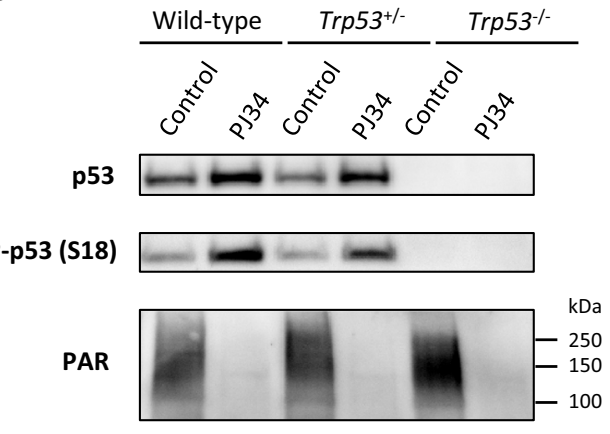

Beta-actin

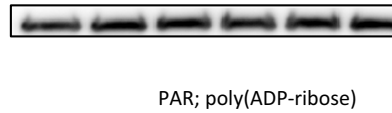

b

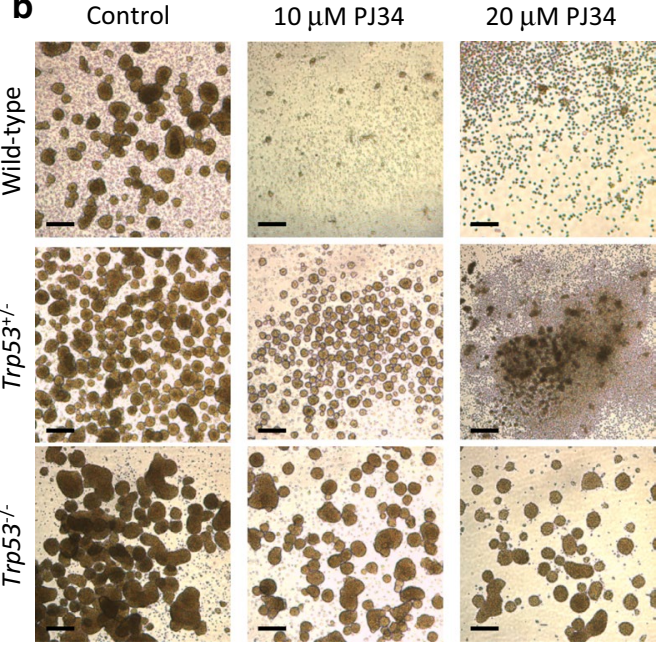

C

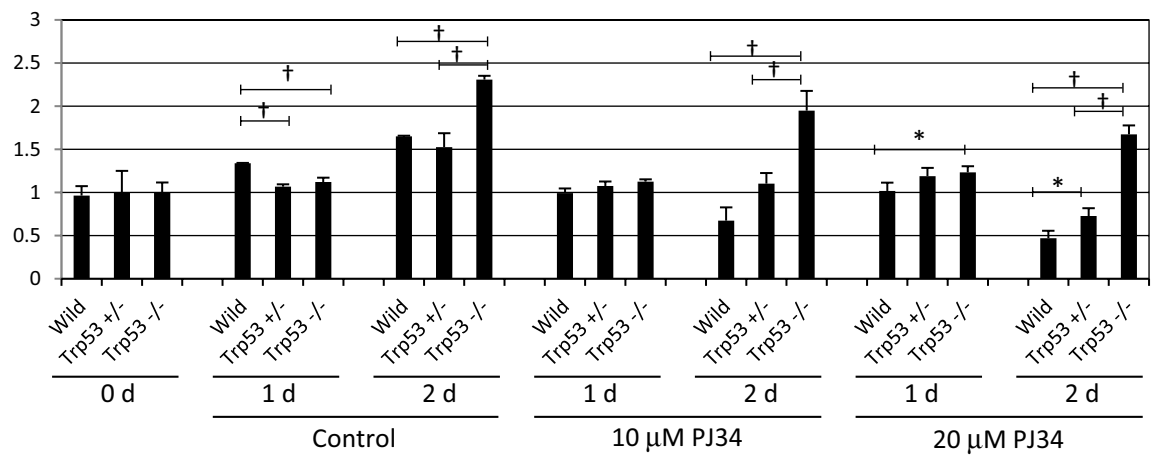

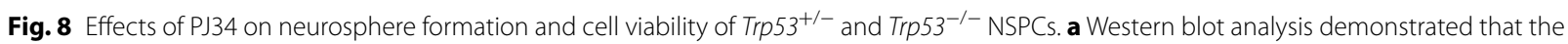
amounts of p53 protein and phosphorylated p53 at Ser 18 were increased by PJ34 in Trp53 $3^{+-}$NSPCs as well as wild-type NSPCs. Automodification of PARP-1 was detectable irrespective of Trp53 genotype. b Neurospheres were detectable in wild-type NSPCs after a 2-day incubation in the absence of PJ34, but were scarcely detectable with 10 or $20 \mu \mathrm{M}$ PJ34. In contrast, neurospheres were still detectable with $10 \mu \mathrm{M}$ PJ34 in Trp53 ${ }^{+/-}$ NSPCs, and with 10 or $20 \mu \mathrm{M}$ PJ34 in Trp53-1- NSPCs. c The increase of MTS-reduction activity of wild-type NSPCs was suppressed by 10 or $20 \mu \mathrm{M}$ PJ34. No suppressive effect of PJ34 was observed in Trp53-/- NSPCS. Data represent the mean value \pm SEM $(n=3) .{ }^{*} p<0.05$ and ${ }^{\dagger} p<0.01$ by oneway ANOVA followed by Tukey's post hoc test. Scale bars in (b), $50 \mu \mathrm{m}$

[46]. PJ34 induces the transcription of PUMA, also known as Bcl-2-binding component 3 (BBC3), which interacts with antiapoptotic Bcl-2 family members, leading to the formation of the free-type of Bax and/or Bak, which are then able to signal apoptosis to the mitochondria [47]. Intriguingly, a balance between PUMA and p21 reportedly determines the onset of cell cycle arrest, or death, in response to exogenous p53 expression. In our study, PJ34 also upregulated another p53 target gene, Noxa, which encodes a BH3-only protein and hence is considered to induce p53-mediated apoptosis in a manner similar to PUMA [45]. Thus, it appears that, in response to PARP inhibition, p53 activates the intrinsic apoptotic pathway by inducing the expression of at least two Bcl-2 pro-apoptotic family members including PUMA and Noxa. The fragment of pro-caspase-9, however, was only slightly detectable, indicating that the involvement of the intrinsic apoptotic pathway was limited.

The interaction of p53 with PARP-1 or poly(ADP-ribosyl)ation of $\mathrm{p} 53$ has been proposed by several investigators [48-51]. The DNA-binding domain of p53 contains some poly(ADP-ribose)-binding sites, which could interfere with its site-specific DNA-binding activity and block its transcriptional function [48, 49]. Alternatively, poly(ADP-ribose) could induce the upregulation of p53 by protecting the protein from proteolytic degradation. One of the poly(ADP-ribose) binding sites in p53 is located near a proteolytic cleavage site, which suggests that polymer binding might protect this sequence from proteolysis [51]. Interestingly, Kanai et al. [52] reported that poly(ADP-ribosyl)ation of p53 blocked the interaction between p53 and the nuclear export receptor Crm1, 


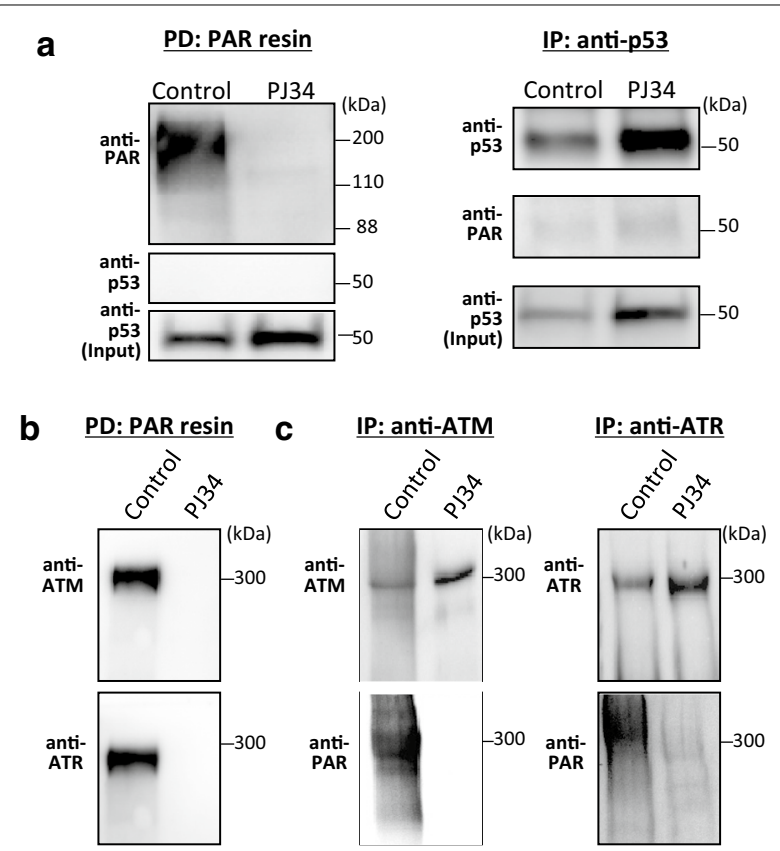

Fig. 9 Poly(ADP-ribosyl)ation of ATM and ATR, but not p53. a Poly(ADP-ribosyl)ated proteins were isolated from cell lysates by highly specific macrodomain poly(ADP-ribose) affinity resin. The resinbound proteins were eluted and analyzed by western blotting with an anti-p53 antibody. Immunoprecipitation was carried out using an anti-p53 antibody. The resulting immunocomplexes were subjected to western blot analysis with anti-p53 and anti-poly(ADP-ribose) antibodies. Poly(ADP-ribosyl)ated p53 was undetectable irrespective of PARP inhibition. $\mathbf{b}$ The same membrane on which the proteins eluted from poly(ADP-ribose) affinity resin were transferred was analyzed by western blotting with anti-ATM and anti-ATR antibodies, resulting in the detection of ATM and ATR. c Immunoprecipitation was performed using an anti-ATM or anti-ATR antibody. Immunocomplexes were subjected to western blot analysis with an anti-ATM or anti-ATR antibody as well as an anti-poly(ADP-ribose) antibody. Poly(ADP-ribosyl) ated ATM and ATR were detectable in the absence of PJ34

followed by the accumulation of p53 in the nucleus and activation of its transactivation function. These findings are not necessarily consistent with ours in which poly(ADP-ribosyl)ated p53 was undetectable. This inconsistency may be due to differences in the type of cell and stress utilized.

Some kinases, such as ATM and ATR, are reportedly responsible for the phosphorylation of p53 at Ser15 (human), i.e., Ser18 (mouse) [53, 54]. Phosphorylation at this site, as observed in our study, and also at Ser20 (human), could inhibit the binding of the p53-degrading enzyme $\mathrm{Mdm} 2$ (Hdm2 in humans), resulting in the stabilization of p53 [53]. Watanabe et al. [55] reported that after the induction of DNA double-strand breaks (DSBs) in MEFs by neocarzinostatin, PARP-1 negatively regulated ATM kinase activity and inhibited phosphorylation of p53 at Ser18. Kedar et al. [56] demonstrated that
ATR interacted with PARP-1 after treatment with methyl methanesulfonate, but this interaction was not detectable after PARP inhibition. Under conditions of PARP inhibition in MEF culture, the cells accumulated in the $S$ phase, probably due to ATR activation. They also demonstrated that ATR is a substrate for poly(ADP-ribosyl)ation by PARP-1 in vitro. These results suggest that poly(ADPribosyl)ation of ATM and/or ATR after DSBs inactivates these kinases, leading to the inhibition of p53 phosphorylation. In our experiments using NSPCs without induction of DSBs, both ATM and ATR were poly(ADPribosyl)ated or inactivated. The PARP inhibitors removed this modification and activated these kinases, resulting in increased phosphorylation of p53 at Ser18 and stabilization of this protein.

PARPs constitute a large family of as many as 17 proteins [1], and PARP-1 is an abundant nuclear protein and the founding member of the PARP family. As poly(ADPribose) is mainly synthesized by PARP-1 after DNA damage, PARP-2 was initially thought to be a "backup of PARP-1." On the contrary, Parp- $2^{-1-}$ mice exhibit impaired spermatogenesis [57], adipogenesis [58], and thymocyte survival [59], although Parp-1 ${ }^{-/-}$mice differentiate normally in these processes. Thus, PARP-2 might have different targets from PARP-1, suggesting that they could play specific biological functions. Interestingly, PARP-1/PARP-2 double knockout mice, which lack poly(ADP-ribosyl)ation, are embryonic lethal [60]. Therefore, both PARP-1 and PARP-2 are thought to conduct critical roles in embryonic development. Our study using specific inhibitors and also shRNAs suggested that PARP-1, but not PARP-2, plays a role in the regulation of p53 functions. In this study, PUMA, a pro-apoptotic protein located in the p53-signaling pathway, was upregulated after treatment with the PARP-2-specific inhibitor UPF1069, which may be due to an unknown function of UPF1069 besides PARP-2-specific inhibition. This possibility should be investigated in further experiments.

Recent reports have provided evidence that intracellular programs, including epigenetic modifications, transcription factors, and extracellular signals, such as various cytokines, are involved in the induction of NSPC differentiation [61]. PARP1 as well as Tet2 are responsible for epigenetic modifications during the reprogramming process [62]. PARP-1 expression was found to be enhanced both in embryonic stem cells and induced pluripotent stem (iPS) cells. PARP-1 activation plays a key role both in the induction of iPS cells and the maintenance of pluripotency [63]. Interestingly, several groups have reported that p53 suppresses iPS cell generation and that its molecular mechanism involves two types of ability of p53: induction of p21, 


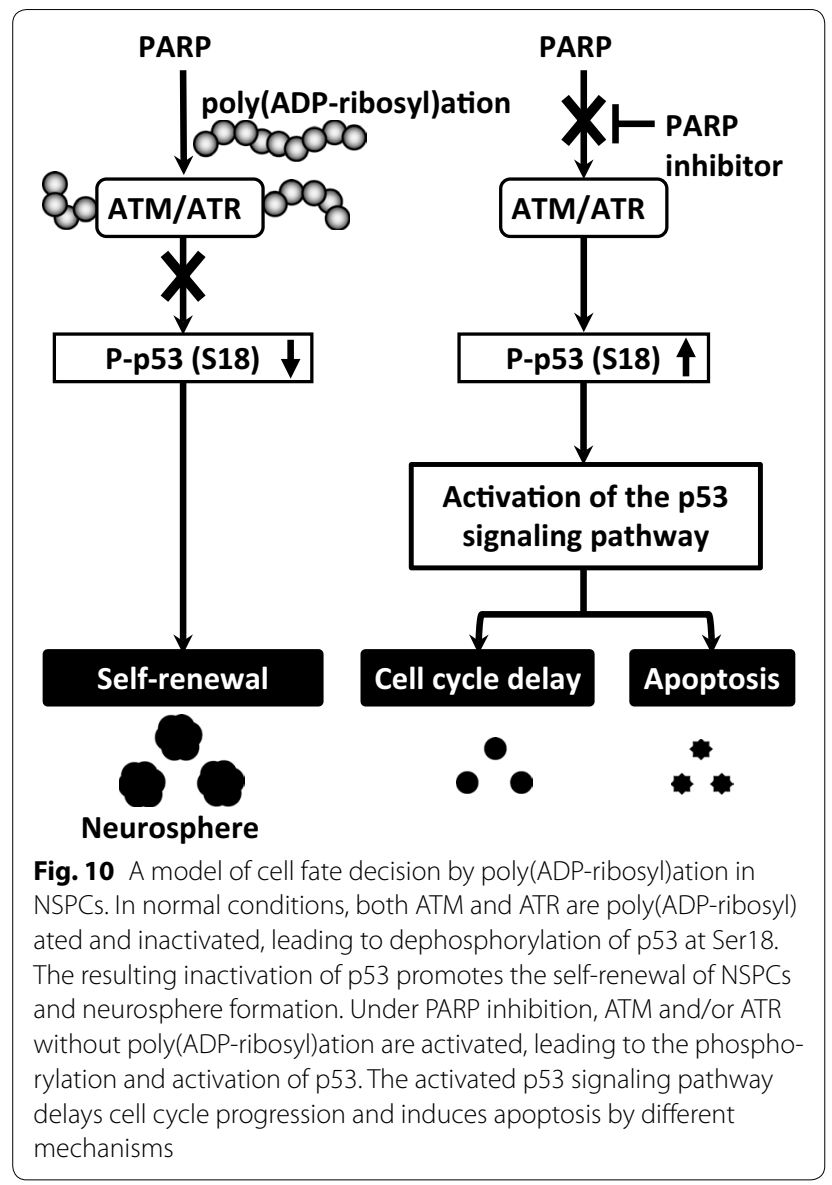

resulting in a restriction of cell cycling, and induction of apoptosis [27, 28, 64]. On the basis of these findings and our predictive model, for the maintenance of NSPC multipotency as well as pluripotency of iPS cells, suppression of $\mathrm{p} 53$ function by PARP-1 might be required.

\section{Conclusions}

Our results indicate the possibility that PARP-1 activation or poly(ADP-ribosyl)ation contributes to the proliferation of NSPCs by advancing the cell cycle and suppressing apoptosis in addition to epigenetic modifications. Inactivation of ATM/ATR and the p53 pathway is suggested to be a mechanism that explains how PARP promotes proliferation and thus maintains NSPC multipotency (Fig. 10).

\section{Authors' contributions}

AO performed almost all experiments and prepared the corresponding figures. SK took over the experiments from AO. AO and SK contributed equally to this work. MT designed the experiments and co-analyzed the results. AM, KF, YK, and HN performed western blotting and RT-PCR. TTN did cell culture, immunocytochemistry, and MTS assay. SO performed gene expression profiling and data analysis. KU participated in the design of the study and coordination, and helped to draft the manuscript. ST directed the research, designed the experiments, co-analyzed the results, and wrote the manuscript. All authors read and approved the final manuscript.

\section{Author details}

${ }^{1}$ Laboratory of Pathophysiology and Pharmacotherapeutics, Faculty of Pharmacy, Osaka Ohtani University, 3-11-1 Nishikiori-kita, Tondabayashi, Osaka 584-8540, Japan. ${ }^{2}$ Bioinformatics, Niigata University Graduate School of Medical and Dental Sciences, 2-5274 Gakkochodori, Chuo-ku, Niigata 951-8514, Japan. ${ }^{3}$ Kobe Tokiwa University, 2-6-2 Otanicho, Nagata-ku, Kobe, Hyogo 653-0838, Japan. ${ }^{4}$ Niigata University Graduate School of Health Sciences, 2-746 Asahimachidori, Chuo-ku, Niigata 951-8518, Japan. ${ }^{5}$ Department of Pharmaceutics, School of Pharmacy and Pharmaceutical Sciences, Mukogawa Women's University, 11-68 Koshien-kyubancho, Nishinomiya, Hyogo 663-8179, Japan.

\section{Acknowledgements}

This work was supported by a Grant-in-Aid for Scientific Research (C) from the Japan Society for the Promotion of Science (JSPS) (Grant Numbers 20590076, 23590097).

\section{Competing interests}

The authors declare that they have no competing interests.

\section{Consent for publication}

All authors consent to publish our manuscript in BMC Neuroscience.

\section{Availability of data and materials}

The data from the microarray analyses are available from the Gene Expression Omnibus (GEO) at NCBI (www.nebi.nlmm.nih.gov/geo) (Accession Number GSE69038). All other relevant data are within the paper.

\section{Ethics approval and consent to participate}

All experimental protocols conformed to the Fundamental Guidelines for Proper Conduct of Animal Experiment and Related Activities in Academic Research Institutions under the jurisdiction of the Ministry of Education, Culture, Sports, Science and Technology, Japan and all experiments were approved by the Animal Experiment Committee of Osaka Ohtani University (No. 1012).

\section{Funding}

MT received a Grant-in-Aid for Scientific Research (C) from the Japan Society for the Promotion of Science (JSPS) (Grant Numbers 20590076, 23590097). The URL is https://www.jsps.go.jp/english/index.html. The funder had no role in study design, data collection and analysis, decision to publish, or preparation of the manuscript.

Received: 1 July 2016 Accepted: 28 December 2016

Published online: 17 January 2017

\section{References}

1. Amé J-C, Spenlehauer C, de Murcia G. The PARP superfamily. BioEssays. 2004;26:882-93.

2. Krishnakumar R, Kraus WL. The PARP side of the nucleus: molecular actions, physiological outcomes, and clinical targets. Mol Cell. 2010;39:8-24.

3. Simonin F, Poch O, Delarue M, de Murcia G. Identification of potential active-site residues in the human poly(ADP-ribose) polymerase. J Biol Chem. 1993;268:8529-35.

4. Alvarez-Gonzalez R, Althaus FR. Poly(ADP-ribose) catabolism in mammalian cells exposed to DNA-damaging agents. Mutat Res. 1989;218:67-74.

5. Wielckens K, George E, Pless T, Hilz H. Stimulation of poly(ADP-ribosyl) ation during Ehrlich ascites tumor cell "starvation" and suppression of concomitant DNA fragmentation by benzamide. J Biol Chem. 1983;258:4098-104

6. Schreiber V, Dantzer F, Ame J-C, de Murcia G. Poly(ADP-ribose): novel functions for an old molecule. Nat Rev Mol Cell Biol. 2006;7:517-28.

7. Szabó C, Dawson VL. Role of poly(ADP-ribose) synthetase in inflammation and ischaemia-reperfusion. Trends Pharmacol Sci. 1998;19:287-98. 
8. Pieper AA, Verma A, Zhang J, Snyder SH. Poly (ADP-ribose) polymerase, nitric oxide and cell death. Trends Pharmacol Sci. 1999:20:171-81.

9. Tanaka S, Takehashi M, lida S, Kitajima T, Kamanaka Y, Stedeford T, et al. Mitochondrial impairment induced by poly(ADP-ribose) polymerase- 1 activation in cortical neurons after oxygen and glucose deprivation. J Neurochem. 2005;95:179-90.

10. Durkacz BW, Shall S, Irwin J. The effect of inhibition of (ADP-ribose)n biosynthesis on DNA repair assayed by the nucleoid technique. Eur J Biochem. 1981;121:65-9.

11. Ruf A, de Murcia G, Schulz GE. Inhibitor and NAD + binding to poly(ADPribose) polymerase as derived from crystal structures and homology modeling. Biochemistry. 1998;37:3893-900.

12. Steffen JD, Brody JR, Armen RS, Pascal JM. Structural implications for selective targeting of PARPs. Front Oncol. 2013;3:301.

13. Baizabal J-M, Furlan-Magaril M, Santa-Olalla J, Covarrubias L. Neural stem cells in development and regenerative medicine. Arch Med Res. 2003;34:572-88.

14. Butti E, Cusimano M, Bacigaluppi M, Martino G. Neurogenic and nonneurogenic functions of endogenous neural stem cells. Front Neurosci. 2014;8:92.

15. Kempermann G. New neurons for "survival of the fittest". Nat Rev Neurosci. 2012;13:727-36

16. Jin K, Minami M, Lan JQ, Mao XO, Batteur S, Simon RP, et al. Neurogenesis in dentate subgranular zone and rostral subventricular zone after focal cerebral ischemia in the rat. Proc Natl Acad Sci USA. 2001;98:4710-5.

17. Hainaut $P$, Hollstein M. p53 and human cancer: the first ten thousand mutations. Adv Cancer Res. 2000;77:81-137.

18. Almog N, Rotter V. Involvement of p53 in cell differentiation and development. Biochim Biophys Acta. 1997:1333:F1-27.

19. Lundberg AS, Hahn WC, Gupta P, Weinberg RA. Genes involved in senescence and immortalization. Curr Opin Cell Biol. 2000;12:705-9.

20. Crook T, Marston NJ, Sara EA, Vousden KH. Transcriptional activation by p53 correlates with suppression of growth but not transformation. Cell. 1994;79:817-27.

21. Pietenpol JA, Tokino T, Thiagalingam S, el-Deiry WS, Kinzler KW, Vogelstein B. Sequence-specific transcriptional activation is essential for growth suppression by p53. Proc Natl Acad Sci USA. 1994;91:1998-2002.

22. el-Deiry WS, Tokino T, Velculescu VE, Levy DB, Parsons R, Trent JM, et al. WAF1, a potential mediator of p53 tumor suppression. Cell. 1993:75:817-25

23. Brugarolas J, Chandrasekaran C, Gordon JI, Beach D, Jacks T, Hannon GJ. Radiation-induced cell cycle arrest compromised by p21 deficiency. Nature. 1995;377:552-7.

24. Harper JW, Adami GR, Wei N, Keyomarsi K, Elledge SJ. The p21 Cdk-interacting protein Cip1 is a potent inhibitor of G1 cyclin-dependent kinases. Cell. 1993:75:805-16.

25. Agarwal ML, Agarwal A, Taylor WR, Stark GR. p53 controls both the G2/M and the $\mathrm{G} 1$ cell cycle checkpoints and mediates reversible growth arrest in human fibroblasts. Proc Natl Acad Sci USA. 1995:92:8493-7.

26. Bates S, Ryan KM, Phillips AC, Vousden KH. Cell cycle arrest and DNA endoreduplication following p21Waf1/Cip1 expression. Oncogene. 1998;17:1691-703.

27. Marión RM, Strati K, Li H, Murga M, Blanco R, Ortega S, et al. A p53-mediated DNA damage response limits reprogramming to ensure iPS cell genomic integrity. Nature. 2009:460:1149-53.

28. Kawamura T, Suzuki J, Wang YV, Menendez S, Morera LB, Raya A, et al. Linking the p53 tumour suppressor pathway to somatic cell reprogramming. Nature. 2009;460:1140-4.

29. Kornblum HI, Zurcher SD, Werb Z, Derynck R, Seroogy KB. Multiple trophic actions of heparin-binding epidermal growth factor (HB-EGF) in the central nervous system. Eur J Neurosci. 1999;11:3236-46.

30. Svendsen CN, Fawcett JW, Bentlage C, Dunnett SB. Increased survival of rat EGF-generated CNS precursor cells using B27 supplemented medium. Exp Brain Res. 1995:102:407-14.

31. Tropepe V, Sibilia M, Ciruna BG, Rossant J, Wagner EF, van der Kooy D. Distinct neural stem cells proliferate in response to EGF and FGF in the developing mouse telencephalon. Dev Biol. 1999;208:166-88.

32. Tsukada T, Tomooka Y, Takai S, Ueda Y, Nishikawa S, Yagi T, et al. Enhanced proliferative potential in culture of cells from p53-deficient mice. Oncogene. 1993;8:3313-22.
33. Ritchie ME, Phipson B, Wu D, Hu Y, Law CW, Shi W, et al. limma powers differential expression analyses for RNA-sequencing and microarray studies. Nucleic Acids Res. 2015:43:e47.

34. Storey JD, Tibshirani R. Statistical significance for genomewide studies. Proc Natl Acad Sci USA. 2003:100:9440-5.

35. Kanehisa M, Goto S, Sato Y, Kawashima M, Furumichi M, Tanabe M. Data information, knowledge and principle: back to metabolism in KEGG. Nucleic Acids Res. 2014;42:D199-205.

36. Joo Y, Ha S, Hong B-H, Kim JA, Chang K-A, Liew H, et al. Amyloid precursor protein binding protein-1 modulates cell cycle progression in fetal neural stem cells. PLoS ONE. 2010:5:e14203.

37. Kupfer GM, Yamashita T, Naf D, Suliman A, Asano S, D'Andrea AD. The Fanconi anemia polypeptide, FAC, binds to the cyclin-dependent kinase, cdc2. Blood. 1997;90:1047-54

38. Banasik M, Komura H, Shimoyama M, Ueda K. Specific inhibitors of poly(ADP-ribose) synthetase and mono(ADP-ribosyl)transferase. J Biol Chem. 1992;267:1569-75.

39. Garcia Soriano F, Virág L, Jagtap P, Szabó E, Mabley JG, Liaudet L, et al. Diabetic endothelial dysfunction: the role of poly(ADP-ribose) polymerase activation. Nat Med. 2001;7:108-13.

40. Sluss HK, Armata H, Gallant J, Jones SN. Phosphorylation of serine 18 regulates distinct p53 functions in mice. Mol Cell Biol. 2004:24:976-84.

41. Lacza Z, Horvath EM, Komjati K, Hortobagyi T, Szabo C, Busija DW. PARP inhibition improves the effectiveness of neural stem cell transplantation in experimental brain trauma. 2003;12:153-9.

42. Sionov RV, Haupt $Y$. The cellular response to $\mathrm{p} 53$ : the decision between life and death. Oncogene. 1999;18:6145-57.

43. Bálint EE, Vousden KH. Activation and activities of the p53 tumour suppressor protein. Br J Cancer. 2001:85:1813-23.

44. Jung Y-S, Qian Y, Chen X. Examination of the expanding pathways for the regulation of p21 expression and activity. Cell Signal. 2010;22:1003-12.

45. Haupt S, Berger M, Goldberg Z, Haupt Y. Apoptosis - the p53 network. J Cell Sci. 2003:116:4077-85.

46. Yuan S, Akey CW. Apoptosome structure, assembly, and procaspase activation. Structure. 2013:21:501-15.

47. Yu J, Zhang L. PUMA, a potent killer with or without p53. Oncogene. 2008;27(Suppl 1):S71-83.

48. Malanga M, Pleschke JM, Kleczkowska HE, Althaus FR. Poly(ADP-ribose) binds to specific domains of p53 and alters its DNA binding functions. Biol Chem. 1998:273:11839-43.

49. Mendoza-Alvarez H, Alvarez-Gonzalez R. Regulation of p53 sequencespecific DNA-binding by covalent poly(ADP-ribosyl)ation. J Biol Chem. 2001;276:36425-30

50. Simbulan-Rosenthal CM, Rosenthal DS, Luo R, Smulson ME. Poly(ADPribosyl)ation of p53 during apoptosis in human osteosarcoma cells. Cancer Res. 1999:59:2190-4.

51. Won J, Chung SY, Kim SB, Byun BH, Yoon YS, Joe CO. Dose-dependent UV stabilization of p53 in cultured human cells undergoing apoptosis is mediated by poly(ADP-ribosyl)ation. Mol Cells. 2006;21:218-23.

52. Kanai M, Hanashiro K, Kim S-H, Hanai S, Boulares AH, Miwa M, et al. Inhibition of Crm1-p53 interaction and nuclear export of p53 by poly(ADPribosyl)ation. Nat Cell Biol. 2007;9:1175-83.

53. Appella E, Anderson CW. Post-translational modifications and activation of p53 by genotoxic stresses. Eur J Biochem. 2001;268:2764-72.

54. Tibbetts RS, Brumbaugh KM, Williams JM, Sarkaria JN, Cliby WA, Shieh SY, et al. A role for ATR in the DNA damage-induced phosphorylation of p53. Genes Dev. 1999:13:152-7.

55. Watanabe F, Fukazawa H, Masutani M, Suzuki H, Teraoka H, Mizutani S, et al. Poly(ADP-ribose) polymerase-1 inhibits ATM kinase activity in DNA damage response. Biochem Biophys Res Commun. 2004;319:596-602.

56. Kedar PS, Stefanick DF, Horton JK, Wilson SH. Interaction between PARP-1 and ATR in mouse fibroblasts is blocked by PARP inhibition. DNA Repair (Amst). 2008;7:1787-98

57. Dantzer F, Mark M, Quenet D, Scherthan H, Huber A, Liebe B, et al. Poly(ADP-ribose) polymerase-2 contributes to the fidelity of male meiosis land spermiogenesis. Proc Natl Acad Sci USA. 2006:103:14854-9.

58. Bai P, Houten SM, Huber A, Schreiber V, Watanabe M, Kiss B, et al. Poly(ADP-ribose) polymerase-2 [corrected] controls adipocyte differentiation and adipose tissue function through the regulation of the activity of the retinoid $x$ receptor/peroxisome proliferator-activated receptorgamma [corrected] heterodimer. J Biol Chem. 2007;282:37738-46. 
59. Yélamos J, Monreal Y, Saenz L, Aguado E, Schreiber V, Mota R, et al. PARP-2 deficiency affects the survival of CD4 + CD8 + double-positive thymocytes. EMBO J. 2006;25:4350-60.

60. Ménissier de Murcia J, Ricoul M, Tartier L, Niedergang C, Huber A, Dantzer F, et al. Functional interaction between PARP-1 and PARP-2 in chromosome stability and embryonic development in mouse. EMBO J. 2003:22:2255-63.

61. Juliandi B, Abematsu M, Nakashima K. Epigenetic regulation in neural stem cell differentiation. Dev Growth Differ. 2010;52:493-504.
62. Doege CA, Inoue K, Yamashita T, Rhee DB, Travis S, Fujita R, et al. Earlystage epigenetic modification during somatic cell reprogramming by Parp1 and Tet2. Nature. 2012;488:652-5.

63. Chiou S-H, Jiang B-H, Yu Y-L, Chou S-J, Tsai P-H, Chang W-C, et al. Poly(ADP-ribose) polymerase 1 regulates nuclear reprogramming and promotes iPSC generation without c-Myc. J Exp Med. 2013;210:85-98.

64. Hong H, Takahashi K, Ichisaka T, Aoi T, Kanagawa O, Nakagawa M, et al. Suppression of induced pluripotent stem cell generation by the p53-p21 pathway. Nature. 2009;460:1132-5.

\section{Submit your next manuscript to BioMed Central and we will help you at every step:}

- We accept pre-submission inquiries

- Our selector tool helps you to find the most relevant journal

- We provide round the clock customer support

- Convenient online submission

- Thorough peer review

- Inclusion in PubMed and all major indexing services

- Maximum visibility for your research

Submit your manuscript at

www.biomedcentral com/submit 